This item was submitted to Loughborough's Research Repository by the author.

Items in Figshare are protected by copyright, with all rights reserved, unless otherwise indicated.

\title{
Cracking behavior of FRC slabs with traditional reinforcement
}

PLEASE CITE THE PUBLISHED VERSION

https://doi.org/10.1617/s11527-011-9791-0

\section{PUBLISHER}

(c) RILEM 2011. Published by Springer

\section{VERSION}

AM (Accepted Manuscript)

\section{PUBLISHER STATEMENT}

This work is made available according to the conditions of the Creative Commons Attribution-NonCommercialNoDerivatives 4.0 International (CC BY-NC-ND 4.0) licence. Full details of this licence are available at: https://creativecommons.org/licenses/by-nc-nd/4.0/

\section{LICENCE}

CC BY-NC-ND 4.0

\section{REPOSITORY RECORD}

Pujadas, Pablo, Ana Blanco, Albert De la Fuente, and Antonio Aguado. 2019. "Cracking Behavior of FRC Slabs with Traditional Reinforcement". figshare. https://hdl.handle.net/2134/32317. 


\title{
Cracking behavior of FRC slabs with traditional reinforcement
}

Pablo Pujadas ${ }^{1}$, Ana Blanco ${ }^{1}$, Albert de la Fuente ${ }^{1}$, Antonio Aguado ${ }^{1}$

${ }^{1}$ Universitat Politècnica de Catalunya, Jordi Girona 1-3, 08028 Barcelona, Spain

\begin{abstract}
The combination of fibers with traditional reinforcement may be a very interesting design solution to achieve more durable and economical structures. This paper deals with the analysis of the aforementioned solution through the study at serviceability and ultimate limit states. For this purpose, a total of eighteen concrete slabs were produced $(3 \times 1 \times 0.2 \mathrm{~m})$ with different reinforcement configurations, types of fibers (steel and plastic) and the fiber dosage used $(0.25 \%$ and $0.50 \%)$. These slabs were tested under the configuration of a four point bending test. The results of this experimental campaign were used in the study of the cracking and deflection of the various types of concrete, tackling the analysis from several points of view.
\end{abstract}

Key words: cracking, fiber-reinforced concrete, traditional reinforcement.

\section{INTRODUCTION}

The traditional uses of fiber reinforced concrete (FRC) have been pavements and subterranean construction [1]. In those applications, fibers were used for the only purpose of improving the durability of the element due to their effectiveness with regard to cracking control at early ages and in the hardened state. Nevertheless, the structural contribution of the fibers was not taken into consideration in terms of project or design. Among the factors that prevented the structural application of the fibers, it is worth highlighting two: the difficulty in estimating the economic advantages of FRC and the lack of experience in their application.

The lack of regulations or recommendations [2] has limited the development of FRC as a competitive structural solution. However, the publication of several regulations and instructions (the German regulation: DBV, 2001 [3], the Italian code CNR-DT 204, 2006 [4] and the Spanish Instruction EHE, 2008 [5]) as well as recommendations for its design (RILEM, 2003 [6]) has caused the application of FRC for structural purposes to increase significantly in recent years.

Likewise, the efforts of the researchers towards understanding the material and its structural response must also be highlighted. There have been numerous experimental campaigns to study the mechanical properties of FRC: the compressive strength [7], the flexural behavior [8], [9] and [10], the pull-out [11], [12], [13] and [14], the tensile strength [15], the tension stiffening [16] and the fatigue in compression [17]. There are also studies that present a hybrid solution that combine different types of fibers: micro and macro steel fibers [18], [19] or steel and plastic fibers (polypropylene polyolefin and nylon) [20], [21], [22]. The purpose of this solution is to optimize the mechanical properties by combining the properties of each type of fiber. In recent years, research has been carried out with the goal of substituting the traditional reinforcement 
of concrete, totally or partially, by structural fibers ${ }^{l}$ given their contribution to resist tensile stresses in the section [23] and [24].

The capacity of the structures to bear internal stresses produced by external loads is as important as the capacity of a structure to resist environmental effects: physical or chemical attacks as well as other deteriorating processes, with a minimum of maintenance. Cracks turn concrete structures into permeable elements, thus entailing a high risk of corrosion. Cracks not only reduce the quality of concrete and make it aesthetically unacceptable, but may also end up rendering the structures unserviceable.

Durability is, together with function and aspect considerations, one of the criteria on which the necessity to limit the crack opening is based. The research works dealing with cracking of FRC [16], [25] and [26] show that the presence of fibers in the concrete helps achieving this goal due to the increase in the crack-bridging capacity.

\section{2 . RESEARCH SIGNIFICANCE}

There are numerous references in the literature to experimental campaigns with FRC elements at the level of sample or specimen [7], [9], [11] and [16]; however, the results regarding the response of FRC elements at full scale are more unusual [24], [27], [28], as well as those of elements with mixed reinforcement [26], [29] and [30]. This is particularly true for elements with mixed traditional reinforcement emerge as a very competitive design solution to obtain more durable and economical structures [23]. Consequently, this paper deals with the analysis of the aforementioned solution from a global point of view pursuing the double aim of:

- Introducing the results from an experimental campaign ([29] and [30]) about concrete slabs with mixed reinforcement (conventional reinforcement and fibers) with several combinations of fibers types and volume.

- Studying and analyzing in detail the role played by fibers in the cracking and deflection response of elements with a mixed reinforcement.

Along with the numerical tools for calculation [31], the information available in this paper provides the project engineer with the opportunity to apply FRC more confidently. Therefore, this research contributes to the knowledge of FRC in the structural field, thus contributing also to spread its use.

\section{EXPERIMENTAL PROGRAM}

\subsection{Specimens}

The elements tested are simply-supported slabs with a length of $3 \mathrm{~m}$, a width of $1 \mathrm{~m}$ and a height of $0.20 \mathrm{~m}$. These slabs have a combined reinforcement consisting of a conventional reinforcement and fibers (except in the case of two control elements which are only reinforced with conventional reinforcement). As shown in figure 1, the conventional reinforcement is made up of seven bars with a diameter of $16 \mathrm{~mm}$ in longitudinal direction and bars with a diameter of $8 \mathrm{~mm}$ every $20 \mathrm{~cm}$ in transversal direction (B500S). The concrete cover is $35 \mathrm{~mm}$ in the longitudinal reinforcement and $50 \mathrm{~mm}$ in the transversal reinforcement.

\footnotetext{
${ }^{1}$ The most recent regulations, such as CNR-DT 204 and EHE-08, make a distinction between structural and non-structural fibers. This change in terminology has significant consequences as regards the application of the fibers.
} 


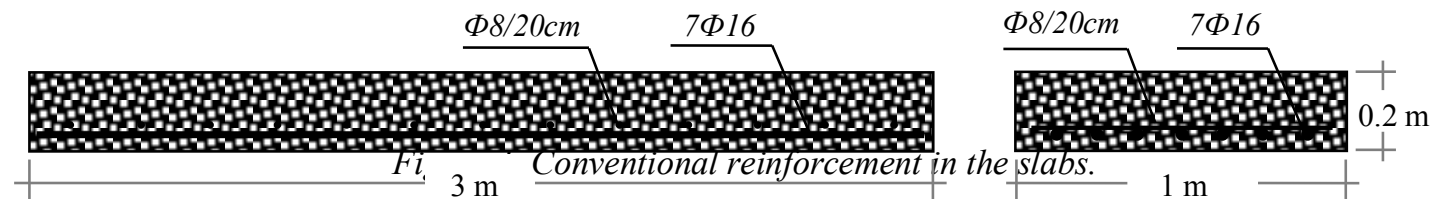

The slabs were cast at the Bekaert S.A. laboratory (Belgium) and subsequently transported to Barcelona in order to be tested at the UPC Structures Technology Laboratory.

\subsection{Materials and mixture}

In addition to the conventional concrete slabs, eight types of FRC were prepared varying the types and contents of fiber ${ }^{2}$. The characteristics of the concrete used are: a water/cement proportion of $0.55,300 \mathrm{~kg} / \mathrm{m}^{3}$ of cement, a maximum aggregate size of 16 $\mathrm{mm}$ and a super-plasticizing content of $1.5 \%$. The consistency of the mixture is soft (S4) according to the Eurocode 2 [32]. The strength class of the fiber reinforced concrete was $\mathrm{C} 25 / 30$.

The fiber content in the elements with mixed reinforcement is $0.25 \%$ of the total volume (which corresponds to $20 \mathrm{~kg} / \mathrm{m}^{3}$ of steel fibers and $2.28 \mathrm{~kg} / \mathrm{m}^{3}$ of polypropylene) and $0.50 \%$ of the total volume $\left(40 \mathrm{~kg} / \mathrm{m}^{3}\right.$ of steel fibers and $4.55 \mathrm{~kg} / \mathrm{m}^{3}$ of polypropylene fibers). Two types of hooked-end steel fibers glued in bundles (SF1 and SF2) and also two types of polypropylene fibers (PF1 and PF2) were used, the characteristics of which are shown in table 1.

\begin{tabular}{lcccc}
\hline \multirow{2}{*}{ Characteristics } & \multicolumn{2}{c}{ Steel Fiber } & \multicolumn{2}{c}{ Polypropylene Fiber } \\
\cline { 2 - 5 } & SF1 & SF2 & PF1 & PF2 \\
\hline Length (mm) & 35 & 60 & 55 & 40 \\
Equivalent diameter (mm) & 0.55 & 0.75 & 0.80 & 0.44 \\
Aspect ratio & 64 & 80 & 70 & 90 \\
Tensile strength (MPa) & 1100 & 1050 & 300 & 620 \\
Modulus of elasticity (GPa) & 210 & 210 & 3.0 & 9.5 \\
Number of fibers per kg & 14500 & 4600 & 39000 & 176000 \\
\hline
\end{tabular}

Table 1. Fiber characteristics (data provided by the manufacturer).

Altogether, eighteen concrete slabs as the one described in figure 1 were produced (two elements per each fiber type and dosage). The notation used to refer to the slabs indicate the type of reinforcement (RC, SF1, SF2, PF1 or PF2), the fiber dosage $(0.25 \%$ or $0.50 \%)$ and the element (A or B; this corresponds to each of the two elements per type of reinforcement and fiber dosage). Therefore, the following would be an example of notation: PF1 $0.25 \%$ A or RC_B. The RC abbreviation corresponds to the elements with conventional reinforcement without fibers (considered to be standard elements), whereas SF1, SF2, PF1 and PF2 correspond to the elements with mixed reinforcement according to the type of fiber.

\footnotetext{
${ }^{2}$ Despite the fact that fibers reduce the workability of concrete, in this case it was not considered necessary to modify the concrete mix of the FRC, because of the workability shown by both types of concrete: RC and FRC.
} 
Apart from the slabs, concrete was also poured on six prismatic samples and on six cubic samples for the characterization of the flexural strength and compressive strength, respectively. All the elements (slabs and samples), were compacted by means of external vibration. The notation used in the case of the samples is the same as the ones used for the slabs (indicating type of fiber and dosage). The characterization tests correspond to the compressive strength in cubic sample $(150 \times 150 \times 150 \mathrm{~mm})$ according to the European regulation EN 12390-3:2009 [33] and to the flexural strength test on the prismatic sample $(150 \times 150 \times 600 \mathrm{~mm})$ according to the regulation EN 14651:2005 [34].

Table 2 shows the results of the bending tests on beams according to [34] for the dosages of $0.25 \%$ and $0.50 \%$. It should be pointed out that these tests present a high scatter (usually above 20\%) as has been reported in literature [35] and [36]. Likewise, the use of macrofibers (as in this case) provides a much higher scatter in the results than if microfibers had been used [37]. In this sense, regarding the global results presented in the following sections, the use of rebars leads to a severe reduction of the scatter associated with the mechanical response of the tested slabs.

\begin{tabular}{|c|c|c|c|c|c|c|c|c|c|c|c|}
\hline \multirow{2}{*}{\multicolumn{2}{|c|}{ Fiber content }} & \multicolumn{5}{|c|}{$0.25 \%$} & \multicolumn{5}{|c|}{$0.50 \%$} \\
\hline & & $f_{L}$ & $f_{R, 1}$ & $f_{R, 2}$ & $f_{R, 3}$ & $f_{R, 4}$ & $f_{L}$ & $f_{R, 1}$ & $f_{R, 2}$ & $f_{R, 3}$ & $f_{R, 4}$ \\
\hline \multirow{3}{*}{5} & Average value (MPa) & 3.84 & 2.55 & 2.44 & 2.22 & 1.99 & 3.62 & 4.1 & 4.18 & 3.94 & 3.49 \\
\hline & Standard deviation $(\mathrm{MPa})$ & 0.33 & 0.89 & 0.95 & 0.85 & 0.71 & 0.45 & 0.89 & 0.96 & 0.92 & 0.84 \\
\hline & $\operatorname{COV}(\%)$ & 8.48 & 34.94 & 38.76 & 38.27 & 35.91 & 12.33 & 21.75 & 22.95 & 23.37 & 24.10 \\
\hline \multirow{3}{*}{$\stackrel{?}{5}$} & Average value (MPa) & 3.35 & 2.96 & 3.16 & 3.23 & 3.1 & 3.12 & 3.93 & 4.49 & 4.56 & 4.62 \\
\hline & Standard deviation $(\mathrm{MPa})$ & 0.17 & 0.67 & 0.83 & 0.87 & 0.82 & 0.37 & 0.69 & 0.97 & 1.03 & 0.93 \\
\hline & $\operatorname{COV}(\%)$ & 5.19 & 22.50 & 26.21 & 27.03 & 26.56 & 11.91 & 17.56 & 21.54 & 22.64 & 20.07 \\
\hline \multirow{3}{*}{$\frac{1}{2}$} & Average value (MPa) & 2.61 & 0.83 & 0.46 & 0.39 & 0.39 & 3.51 & 1.15 & 0.95 & 0.94 & 0.97 \\
\hline & Standard deviation $(\mathrm{MPa})$ & 0.19 & 0.18 & 0.10 & 0.10 & 0.08 & 0.22 & 0.27 & 0.25 & 0.27 & 0.29 \\
\hline & $\operatorname{COV}(\%)$ & 7.36 & 21.47 & 20.86 & 25.22 & 20.74 & 6.13 & 23.32 & 25.73 & 28.15 & 30.47 \\
\hline \multirow{3}{*}{$\frac{N}{2}$} & Average value (MPa) & 3.21 & 1.28 & 1.15 & 1.08 & 0.97 & 2.98 & 1.77 & 1.65 & 1.59 & 1.52 \\
\hline & Standard deviation $(\mathrm{MPa})$ & 0.21 & 0.06 & 0.12 & 0.12 & 0.04 & 0.32 & 0.40 & 0.41 & 0.38 & 0.36 \\
\hline & $\mathrm{COV}(\%)$ & 6.42 & 4.86 & 10.22 & 10.67 & 4.63 & 10.59 & 22.81 & 24.94 & 23.77 & 23.56 \\
\hline
\end{tabular}

Table 2. Flexural strength and residual strengths obtained from the bending tests according to [34].

The results in table 2 show the difference in post-cracking behavior between the steel fibers with hooked ends and the polypropylene macrofibers. The latter presents lower residual strengths due to the low modulus elasticity in comparison with steel fibers. Considering a CMOD of $3.5 \mathrm{~mm}$, the residual flexural strengths shown are higher for PF2 elements than PF1 elements: $146 \%$ higher in the case of the $0.25 \%$ content, and a $56 \%$ for the content of $0.50 \%$. Steel fibers, in $0.50 \%$ content, show an increase with regard to PF1 much more significant with percentages of $260 \%$ for the SF1 fibers and of $376 \%$ for the SF2 fibers.

The fact that the SF2 fibers have a larger diameter than the SF1 fibers allows the former to withstand higher tensile stresses. Likewise, the transfer length (the length necessary to develop its maximum strength capacity by means of a bond stress transfer mechanism) has an influence over the anchorage capability of the fibers. The long

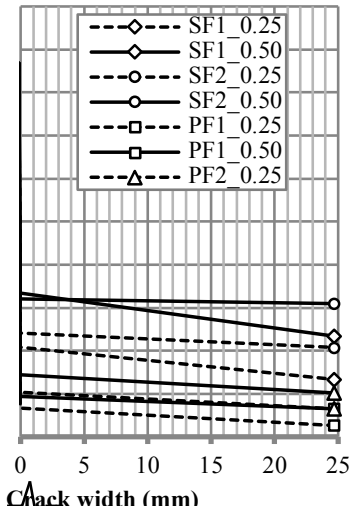

CAack width (mm)
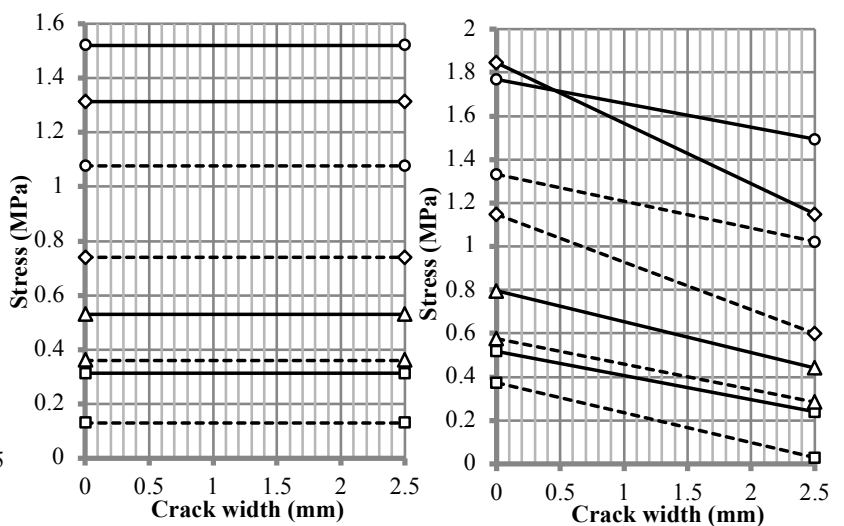
fibers (SF2) with a length of $60 \mathrm{~mm}$ (see table 1) turn out to be more active in bridging the cracks when the cracks are bigger, providing a more stable post-cracking response. However, the shortest fibers (SF1) with a length of $35 \mathrm{~mm}$ (see table 1), in spite of being very efficient for the control of smaller cracks (since there is a higher amount of fibers crossing the crack mouth opening with respect to concrete with longer fibers), become less active as the crack increases due to the fact that they are subjected to higher pullout forces [18]. Finally, they reach a point when the fiber length embedded in the concrete is insufficient for them to take part in the transfer of stress mechanisms. The constitutive laws can be deduced from the results obtained by means of the 3-point bending tests. The constitutive models presented in figure $2 \mathrm{a}$ correspond to the one proposed by RILEM [6] which consists of a trilinear $\sigma-\varepsilon$ model. The models presented in figure $2 \mathrm{~b}$ and $2 \mathrm{c}$ correspond, respectively, to the simplified stress-crack opening constitutive laws: a plastic rigid behaviour and a linear postcracking behavior proposed in the new fib Model Code [38].

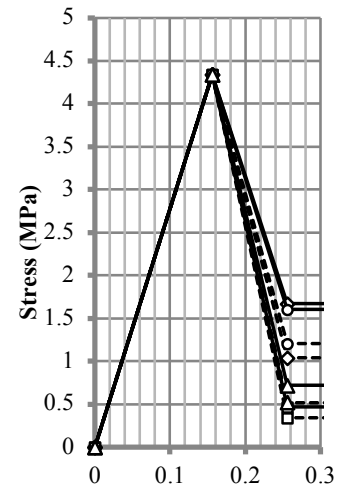

Figure 2. (a) RILEM trilinear model; (b) MC Rigid-plastic model; (c) MC Linear model.

Further analysis of the main models and constitutive equations proposed Europe-wide for the use of structural fiberreinforced concrete [3], [6], [4] and [5]) and a detailed comparative study to determine the capacity of each model to predict FRC structural behavior with the slabs data here analyzed can be found in [39].

\subsection{Test setup and procedure}

The tests were carried out with an MTS piston and the setup follows an isostatic configuration similar to a 4 point bending test (see figure 3 ). The rotation in both supports is free and the horizontals movements are restrained only in one of the supports, as indicated in figure 3.

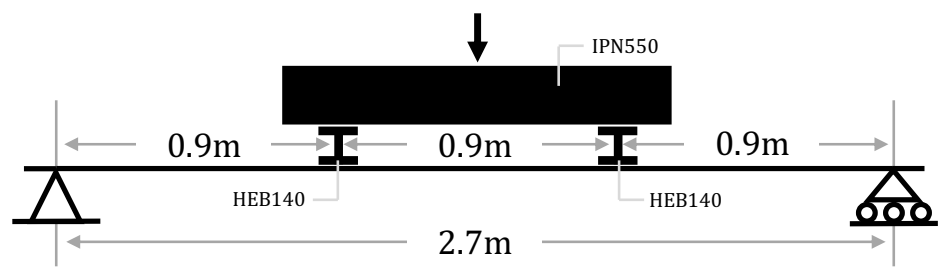

Figure 3. Test setup and dimensions.

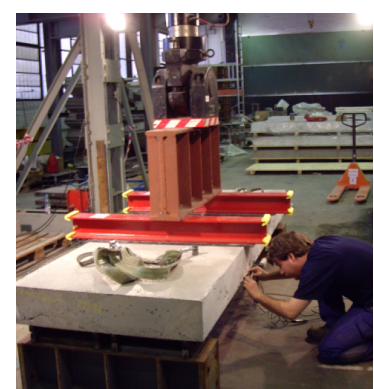

The tests were carried out at the Laboratory of Structure Technology by means of a MTS load frame with a maximum capacity of $1000 \mathrm{kN}$. The piston of the load frame is connected in one end to a gantry crane by means of a tridimensional joint. The slabs are loaded by means of a stiffened steel beam (IPN 550) (see figure 3) that is connected to the piston. The load transmitted by the mentioned beam is transferred to two steel beams (HEB 140) located all along the width of the slabs. These two other steel beams ensure a continuous loading line in the width of the element and are designed to have a minimum influence in the results of the test. Between the two steel beams and the top of the slab, a layer of neoprene, is placed to ensure full contact in the loading surface. 
The test is performed with displacement control, gathering all yielding phenomena that occur during the test, at a constant displacement rate of $0.025 \mathrm{~mm} / \mathrm{s}$. The loading procedure consists of stages of $20 \mathrm{kN}$ up to $100 \mathrm{kN}(45 \%$ of the final load in the tests of RC elements), moment in which the load is applied continuously without stopping. Each of the mentioned stages is twenty minutes long approximately; during which the last ten minutes are used to mark the cracks in both sides of the slabs, taking photographs of the cracks in order to subsequently draw the crack pattern thus plotting the history of cracking propagation.

\subsection{Measurements}

During the test, the main variable to be measured, apart from displacement, was crack width. With this aim, displacement transducers were placed horizontally on both sides of the slab in order to measure crack opening. These transducers were arranged in such a way that they measured the central $45 \mathrm{~cm}$ of the slab where pure-bending took place. A third transducer was placed, in the midspan section, in order to determine deflection.

With the records from those measurements it was possible to analyze parameters related to cracking, resistant capacity, stiffness loss, number of cracks, crack spacing and crack width and distribution.

\section{RESULTS}

The results presented in this paper are structured in three main sections depending on the variables analyzed: crack number and spacing, crack width and displacement. In the analysis of both crack width and displacement, a thorough study is performed, taking into consideration the serviceability limit state and the ultimate limit state with the purpose of obtaining a global view of the behavior of the elements.

\subsection{Crack number and spacing}

The analysis of the spacing between cracks experimentally obtained was limited to the central $90 \mathrm{~cm}$ of the slab so as to prevent a possible interaction with cracks due to shear in the area close to the supports. The set of diagrams in figure 4 shows the crack patterns for the tested slabs following the previously mentioned nomenclature. 
RC_A

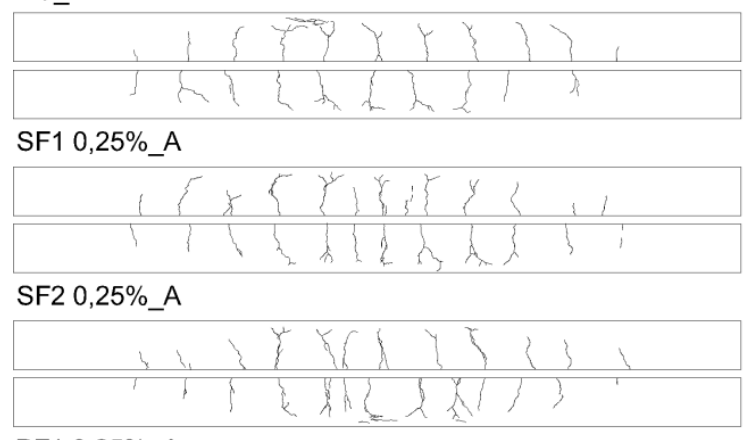

PF1 0,25\%_A

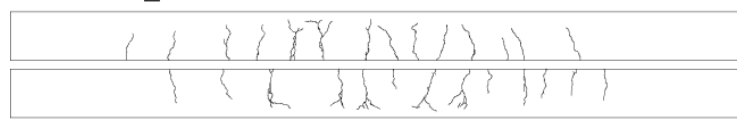

PF2 0,25\%_A

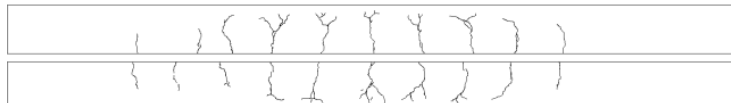

SF1 0,50\%_A

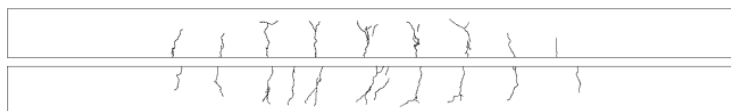

SF2 0,50\%_A

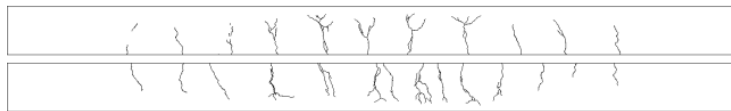

PF1 0,50\%_A

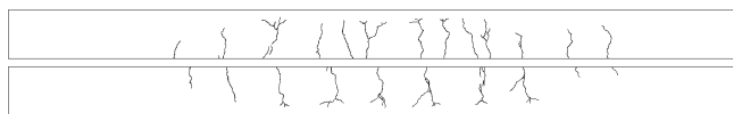

PF2 0,50\%_A

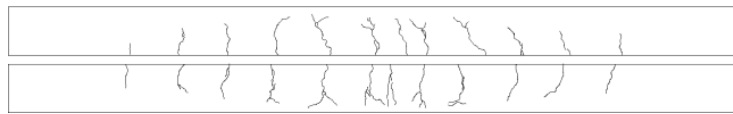

RC_B

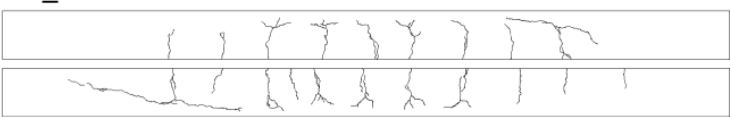

SF1 0,25\%_B

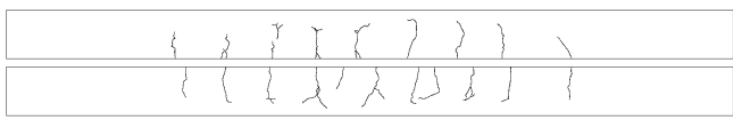

SF2 $0,25 \% \_B$

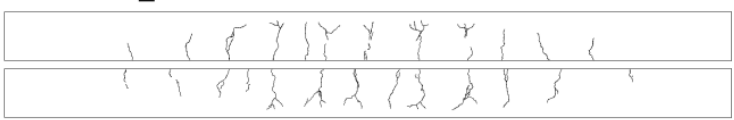

PF1 0,25\%_B

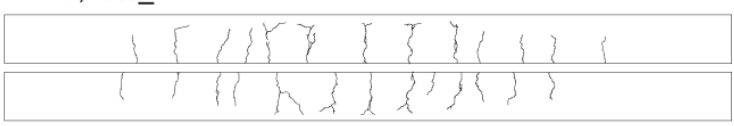

PF2 0,25\%_B

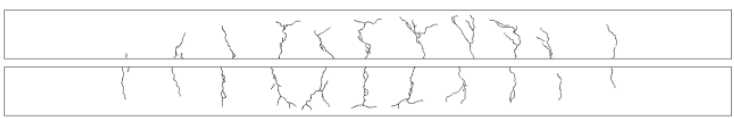

SF1 0,50\%_B

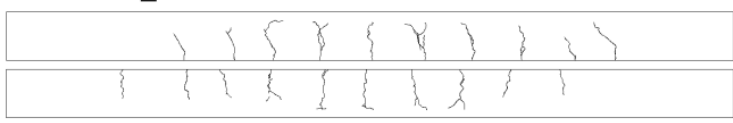

SF2 $0,50 \% \_B$

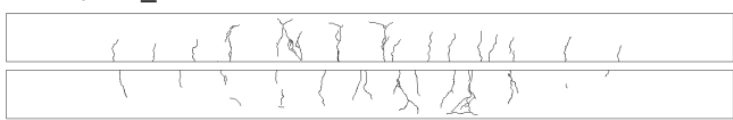

PF1 0,50\%_B

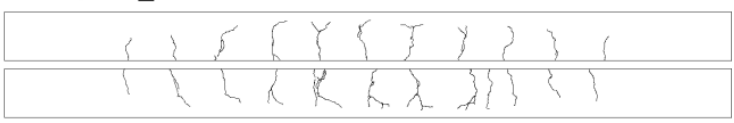

PF2 0,50\%_B

Figure 4. Crack pattern of specimens.

As previously proved in [40], FRC elements tend to present deeper positions of the neutral axis with respect to RC elements, thus, smaller crack spacing and larger number of shorter cracks is expected to occur. In this respect, the same phenomenon was observed in this experimental campaign (see figure 4 and table 3 ). As it can be observed in the crack pattern, crack localization did not occur however ramification was observed in many of the cracks, especially in those with higher dosage. Likewise, it should be pointed out that for the slab RC_B, shear cracks have developed during the test. This sort of cracks has not appeared in any of the other slabs.

Table 3 shows the mean values of number of cracks and crack spacing for the tested elements. Likewise, table 3 also includes the mean crack spacing values obtained through the formulation proposed by the RILEM [6] and CNR-DT 204 [4] for elements reinforced with fibers and traditional reinforcement.

\begin{tabular}{ccccc}
\hline $\begin{array}{c}\text { Type } \\
\text { of } \\
\text { fiber }\end{array}$ & $\begin{array}{c}\text { Fiber } \\
\text { content } \\
(\%)\end{array}$ & $\begin{array}{c}\text { Average } \\
\text { number of } \\
\text { cracks }\end{array}$ & $\begin{array}{c}\text { Average } \\
\text { crack } \\
\text { spacing (cm) }\end{array}$ & $\begin{array}{c}\text { Crack spacing prediction } \\
\text { in }\end{array}$ \\
\hline RC & - & 10 & 19.0 & $\begin{array}{c}\text { RILEM and CNR-DT 204 } \\
\text { (cm) }\end{array}$ \\
\hline
\end{tabular}




\begin{tabular}{lllll}
\hline SF 1 & 0.25 & 11 & 15.6 & \multirow{2}{*}{13.5} \\
\hline SF 1 & 0.50 & 10 & 18.6 & \multirow{2}{*}{10.8} \\
\hline SF 2 & 0.25 & 12 & 15.9 & \multirow{2}{*}{12.5} \\
\hline SF 2 & 0.50 & 13 & 14.1 & \multirow{2}{*}{9.5} \\
\hline PF 1 & 0.25 & 13 & 14.4 & 17.9 \\
\hline PF 1 & 0.50 & 12 & 19.2 & \\
\hline PF 2 & 0.25 & 10 & 16.0 & \\
\hline PF 2 & 0.50 & 12 &
\end{tabular}

Table 3. Average number of cracks, mean crack spacing and crack spacing prediction (based on RILEM and CNR-DT 204 formulation).

In general terms, in table 3 it can be observed that the addition of fibers causes the appearance of a higher number of cracks and, consequently, smaller spacing between them. This behavior is mainly due to: (1) the enhancement of the bond between rebars and concrete due to the presence of fibers, leading to the reduction of the bond transfer length [16], [41] and [42] and (2) the post-cracking behavior of the concrete reinforced with fibers.

Crack spacing is directly related to the transfer length $\left(l_{t}\right)$ that establishes the limits of spacing [16]. That would explain why the addition of PF2 fibers (of $40 \mathrm{~mm}$ ) in the amount of $0.25 \%\left(2.28 \mathrm{~kg} / \mathrm{m}^{3}\right)$ does not mean an improvement in crack spacing, and why its contribution is only evident with greater amounts. It can be observed that in the slabs with PF1 and SF1 fibers the increase of the amount of fibers does not involve a reduction in crack spacing (even though it is smaller than that of slabs without fibers). This phenomenon leads to think that with small and moderate amounts (lower than $0.75 \%$ in volume), the increase in fiber dosage has no direct influence over crack spacing [26].

The crack spacing prediction in table 3 is obtained by means of the formulation presented by Vandewalle [26] on the basis of the experiences in [26] and of Tan et al. [40] with beam-type elements (later included in [4] and [6]). This formulation includes parameters regarding the geometry of the fibers (length and diameter), but not regarding the amount of fibers. For this reason the mean spacing values for the amounts of $0.25 \%$ and $0.50 \%$ of the volume are the same. Furthermore, if the experimental results are compared to the prediction, it can be seen that the latter underestimates the value of the mean crack spacing.

These differences are due to the fact that the equations developed on the basis of tests on beam elements or unidirectional slabs underestimate cracking width in bidirectional slabs and plates because the behavior of bidirectional slabs and plates is different from that of beams or unidirectional slabs. Therefore, the methods developed on the basis of beam elements cannot be directly applied in these cases. For those cases, an equation combining the effect of the reinforcement in both directions should be proposed [43].

On the other hand, in the slabs without fibers crack spacing is clearly ruled by the transversal reinforcement (bars with a diameter of $8 \mathrm{~mm}$ every $20 \mathrm{~cm}$ ). These results show a fact also sanctioned by practice: that the existence of a transversal reinforcement makes the cracks line up with it and even favors the beginning or the propagation of cracking, as a consequence of the reduction of the area of collaborating concrete in 
those sections. Detailed studies about the contribution of the transversal reinforcement can be found in [44] and [45].

\subsection{Crack width}

As has been previously mentioned, the crack opening of the slabs was recorded by means of displacement transducers. In each case the average of crack width in the study area (the central $45 \mathrm{~cm}$ of the slab) and in both sides of the slab was measured. In the set of graphs presented below, the load stages performed have been removed in order to make the reading and interpretation of the graphs easier.

\subsubsection{Serviceability limit state analysis}

Crack widths of $0.3 \mathrm{~mm}$ (maximum value admitted by RILEM [6] for the class of exposition II) and of $0.5 \mathrm{~mm}$ (admitted in cases like that of CSTC pavements [46]) were considered as reference crack widths for this research study. Then, in order to show the behavior of the elements in the serviceability limit state, curves of average crack width (up to $0.5 \mathrm{~mm}$ ) are presented, according to the load applied for each type and the fiber content (see set of graphs in figure 5).

The curves in figure 5 show the results obtained for the two elements of each type of fiber and dosage (designated as element A and element B, ex: SF1 $0.25 \%$ A and SF1 $0.25 \%$ B). The values in those curves correspond to the average of the crack width measured in both sides of the slab.
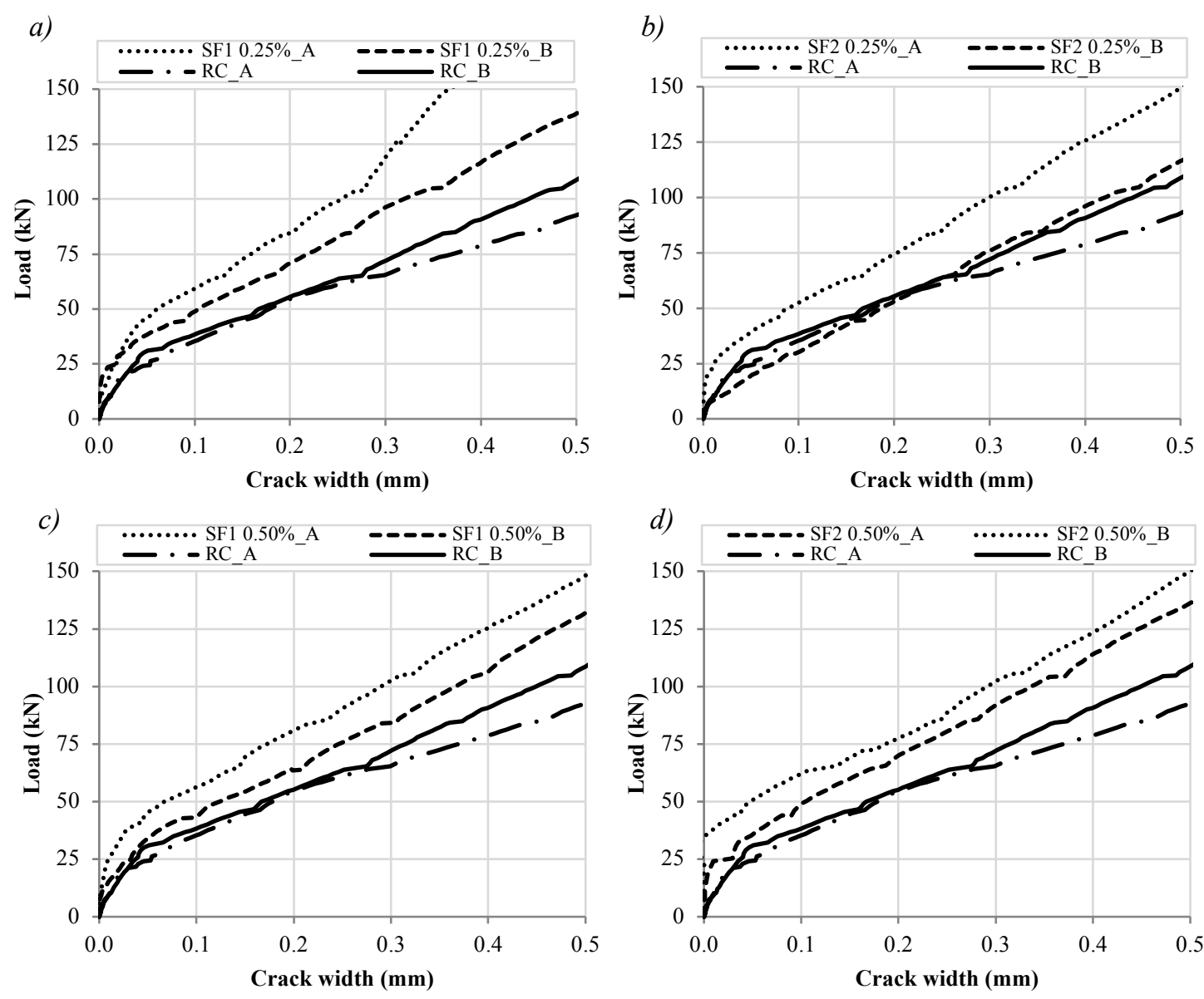

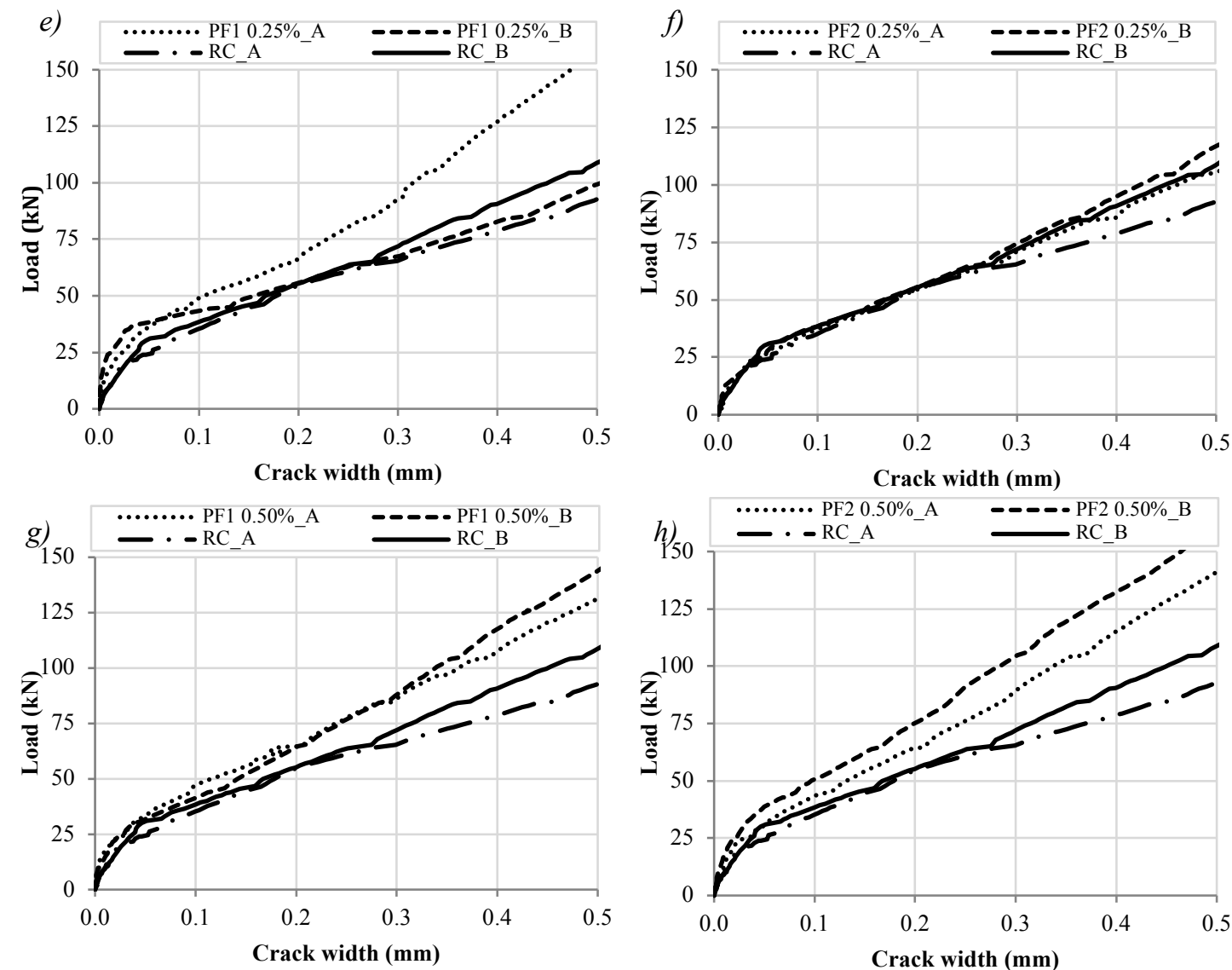

Figure 5. Load-crack width curves in serviceability limit state for steel fibers (a), (b), (c), (d) and polypropylene fibers (e), (f), (g), (h) for both fiber contents: $0.25 \%$ and $0.50 \%$ in volume.

In figure 5a (steel fibers in the amount of $0.25 \%$ in volume) it is observed that the shortest fibers (SF1) enable a better cracking control. The SF1 0.25\%_A element is the one showing the best behavior, and the SF1 $0.25 \%$ B is only slightly surpassed by one of the SF2 $0.25 \%$ A elements (figure 5b). In figure 5c, as the amount of fibers has been doubled, the most efficient behavior of the short fibers observed in figure $5 \mathrm{a}$ is not so evident, since both the SF1 and SF2 elements, in figure 5d, show a very similar response.

In figures $5 \mathrm{e}$ and $5 \mathrm{f}$ (amount of fibers of $0.25 \%$ in volume) it can be observed that the elements with polypropylene fibers, both PF1 and PF2, show a behavior which is very similar to that of the RC elements. Only in figure 5c does the PF1 $0.25 \%$ A element drift away from the rest with a more favorable response as regards cracking control during the in-service stage. However, since this time the dosage was twice the amount of the previous one, the behavior is significantly different; in figures $5 \mathrm{~g}$ and $5 \mathrm{~h}$, the PF1 and PF2 elements show an improvement in their response to cracking in comparison with the RC elements.

The presence of the fibers throughout the whole concrete section results in an increase in toughness and in better cracking control since, contrary to what happens in a conventional concrete, they work throughout the whole tensile block. This behavior, already shown in the set of graphs in figure 5, is analyzed in detail in table 4, which presents the load values corresponding to the crack widths of $0.3 \mathrm{~mm}$ and $0.5 \mathrm{~mm}$ for each element. 


\begin{tabular}{cccc}
\hline $\begin{array}{c}\text { Type of } \\
\text { concrete }\end{array}$ & $\begin{array}{c}\text { Fiber content } \\
(\mathbf{\%})\end{array}$ & $\begin{array}{c}\text { Load }(\mathbf{k N}) \mathbf{a t} \\
\mathbf{w}=\mathbf{0 . 3} \mathbf{~ m m}\end{array}$ & $\begin{array}{c}\text { Load }(\mathbf{k N}) \text { at } \\
\mathbf{w}=\mathbf{0 . 5} \mathbf{~ m m}\end{array}$ \\
\hline RC & - & 69.0 & 101.5 \\
\hline SF 1 & 0.25 & 88.5 & 124.5 \\
\hline SF 2 & 0.25 & 88.0 & 132.5 \\
\hline SF 1 & 0.50 & 89.1 & 139.8 \\
\hline SF 2 & 0.50 & 96.5 & 144.5 \\
\hline PF 1 & 0.25 & 85.0 & 119.8 \\
\hline PF 2 & 0.25 & 72.8 & 107.3 \\
\hline PF 1 & 0.50 & 85.0 & 131.5 \\
\hline PF 2 & 0.50 & 75.8 & 116.3 \\
\hline
\end{tabular}

Table 4. Values of load for crack widths of $0.3 \mathrm{~mm}$ and $0.5 \mathrm{~mm}$.

The values in table 4 are indicative of the remarkable increase in the load for a certain value of crack width due to the addition of fibers. Observing the reference value of $0.3 \mathrm{~mm}$ for an amount of fibers of $0.50 \%$, the mean increase of the load with regard to that obtained with the slabs without fibers (RC) is of $29.1 \%$ for the SF1 fibers and $39.9 \%$ for the SF2 fibers; whereas for the same dosage but with plastic fibers an increase of $23.2 \%$ is obtained for the PF1 fibers and a $9.9 \%$ for the PF2 fibers. For the reference value of $0.5 \mathrm{~mm}$, with the same amount, these load increase values, with regard to the RC elements, are $37.7 \%, 42.4 \%, 29.6 \%$ and $14.6 \%$ for the SF1, SF2, PF1 and PF2 elements, respectively. Therefore, as crack width increases, the difference is accentuated.

\subsubsection{Ultimate limit state analysis}

If we extend the analysis to larger crack widths, we can analyze the behavior of the elements in ultimate limit state. Figure 6 show the global response of the tested slabs for the contents of $0.25 \%$ and $0.50 \%$ in volume and steel and polypropylene fibers. 


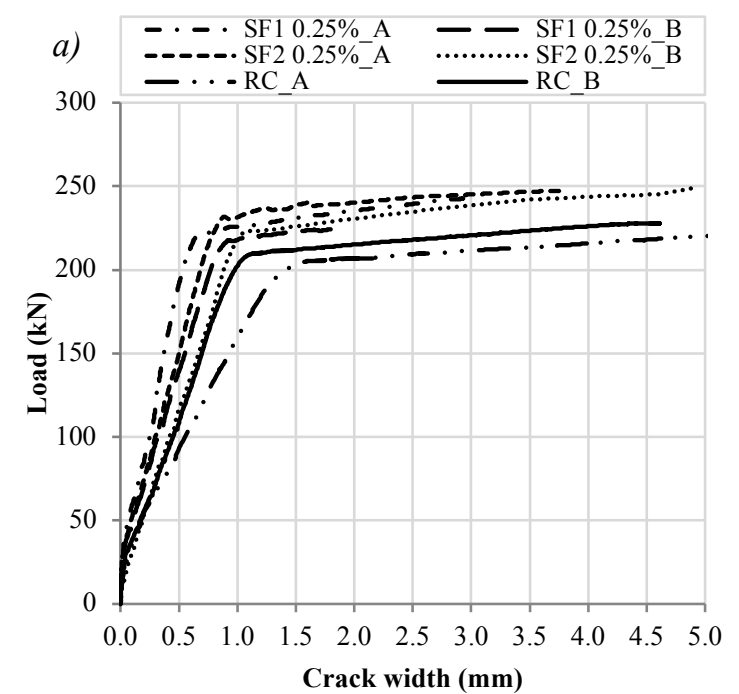

b)
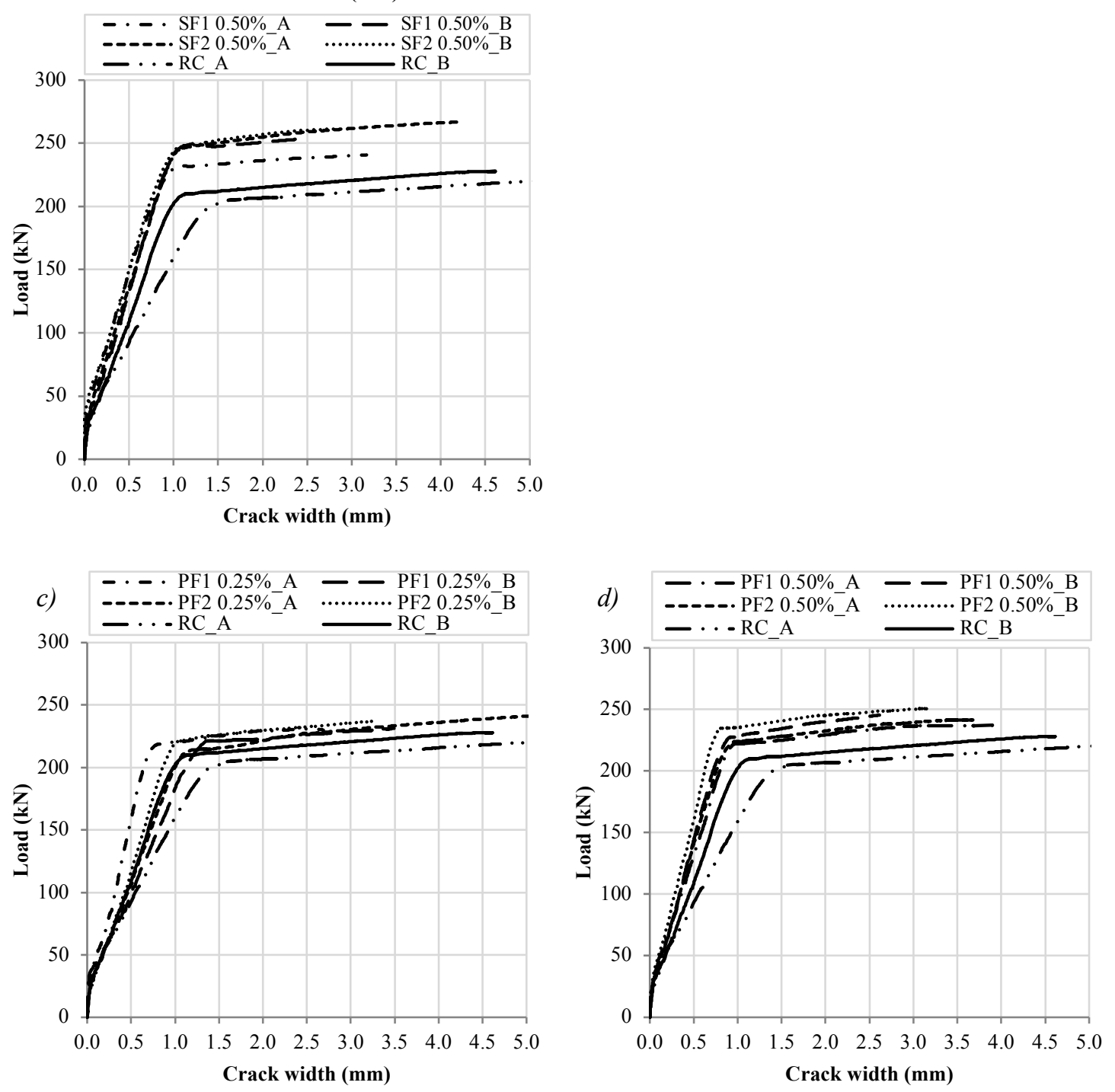

Figure 6. Load-crack width curves for steel (a),(b) and polypropylene fibers (c),(d).

The crack widths for $100 \mathrm{kN}, 150 \mathrm{kN}$ and $200 \mathrm{kN}$ are gathered in table 5 (as well as the values obtained applying the RILEM formulation [6]). The majority of the cracks along the whole length of the element were already formed at those load levels. Thus, it 
can be considered a stabilized cracking where the contribution to the strength of concrete is practically negligible (except between cracks, due to the stiffening mechanism of concrete and the elastic part in the hollow of the crack). Consequently, the responsibility for absorbing the strain stresses belongs to the fibers and the rebars.

\begin{tabular}{cccccccc}
\hline \multirow{2}{*}{$\begin{array}{c}\text { Type of } \\
\text { concrete }\end{array}$} & \multirow{2}{*}{$\begin{array}{c}\text { Fiber } \\
\text { content }\end{array}$} & \multicolumn{2}{c}{ At 100 kN } & \multicolumn{2}{c}{ At 150 kN } & \multicolumn{2}{c}{ At 200 kN } \\
\cline { 3 - 8 } & & Measured & RILEM & Measured & RILEM & Measured & RILEM \\
\hline RC & - & 0.50 & - & 0.80 & - & 1.19 & - \\
\hline SF 1 & $0.25 \%$ & 0.32 & 0.152 & 0.55 & 0.271 & 0.77 & 0.393 \\
\hline SF 1 & $0.50 \%$ & 0.33 & 0.104 & 0.54 & 0.221 & 0.77 & 0.344 \\
\hline SF 2 & $0.25 \%$ & 0.36 & 0.110 & 0.58 & 0.208 & 0.78 & 0.307 \\
\hline SF 2 & $0.50 \%$ & 0.32 & 0.088 & 0.53 & 0.182 & 0.75 & 0.283 \\
\hline PF 1 & $0.25 \%$ & 0.40 & 0.186 & 0.64 & 0.311 & 0.88 & 0.426 \\
\hline PF 1 & $0.50 \%$ & 0.35 & 0.237 & 0.55 & 0.299 & 0.76 & 0.413 \\
\hline PF 2 & $0.25 \%$ & 0.44 & 0.138 & 0.68 & 0.224 & 0.90 & 0.312 \\
\hline PF 2 & $0.50 \%$ & 0.31 & 0.127 & 0.49 & 0.213 & 0.68 & 0.320 \\
\hline
\end{tabular}

The results from the tests ("Measured" in table 5) indicate that the elements with SF1 fibers show an improvement with regard to the RC elements, for which the amount of fibers does not seem to be significant, since they present results very similar for the two amounts used. In the case of the SF2 elements, a higher increase takes place when changing from $0.25 \%$ to $0.50 \%$ in volume. Between the elements with polypropylene fibers, the PF1 show a better response for an amount of $0.25 \%$ in volume, and the PF2 for $0.50 \%$. Still, the best response of the PF2 elements with regard to the rest of the elements with the amount of $0.50 \%$ in volume for the three load levels may be indicative of some irregularity in the placing of the reinforcements or of a higher number of fibers in the hollow of the crack.

In some of the elements with steel fibers a position of the reinforcement higher than the theoretical one was detected. This phenomenon gives rise to a smaller mechanical arm and, consequently, to a worse response than expected. Nevertheless, in the elements with PF2 fibers this irregularity was not detected. Likewise, the PF2 fiber, due to its properties (see table 1), shows a higher amount of fibers in the section than the rest of the fibers, which favors cracking control. These two factors may be the reason for the results in table 5 .

The results in table 5 also show that the RILEM formulation for the prediction of crack width underestimates the values of crack width for this particular case of study. The larger difference between the values is observed for PF1 $0.50 \%$ in all three load levels $(100 \mathrm{kN}, 150 \mathrm{kN}$ and $200 \mathrm{kN})$ with values $67.7 \%, 54.3 \%$ and $54.3 \%$ respectively.

\subsubsection{Analysis of the increment in load-crack width curve}

Given the influence of traditional reinforcement in the flexural behavior of the slabs, it is interesting to study the results in relative terms, in other words, to present the results of the FRC in terms of the increment of load due to the presence of fibers with regard to the load obtained for the RC slabs. For this purpose, the increment of average load (in \%) has been calculated for several values of crack width (ranging from $0 \mathrm{~mm}$ to $2.0 \mathrm{~mm}$ ). Figures 7 and 8 present the results for steel fibers and plastic fibers respectively. Generally speaking, it can be considered from the results in both figures 
that the increment in average load for a given crack width increases up to a certain value and from that value onwards it noticeably decreases until it becomes stable.

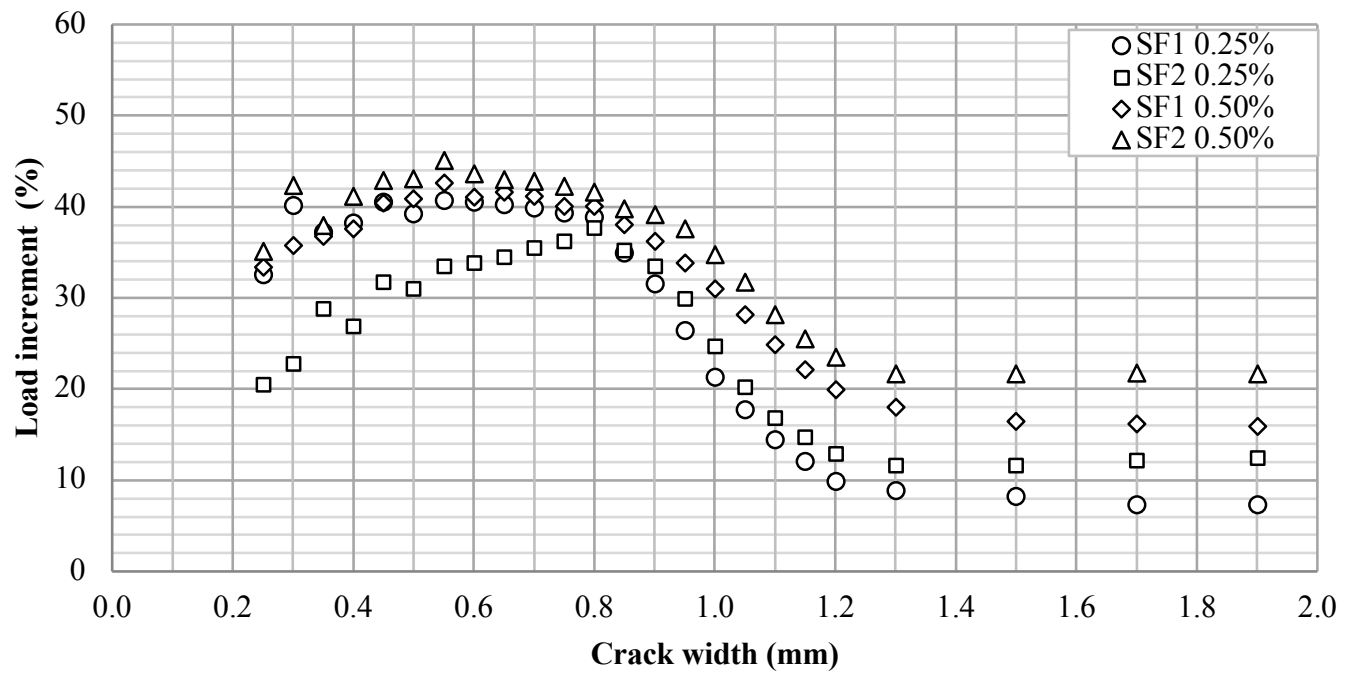

Figure 7. Percentage of increment in load-crack width curve. Steel fibers.

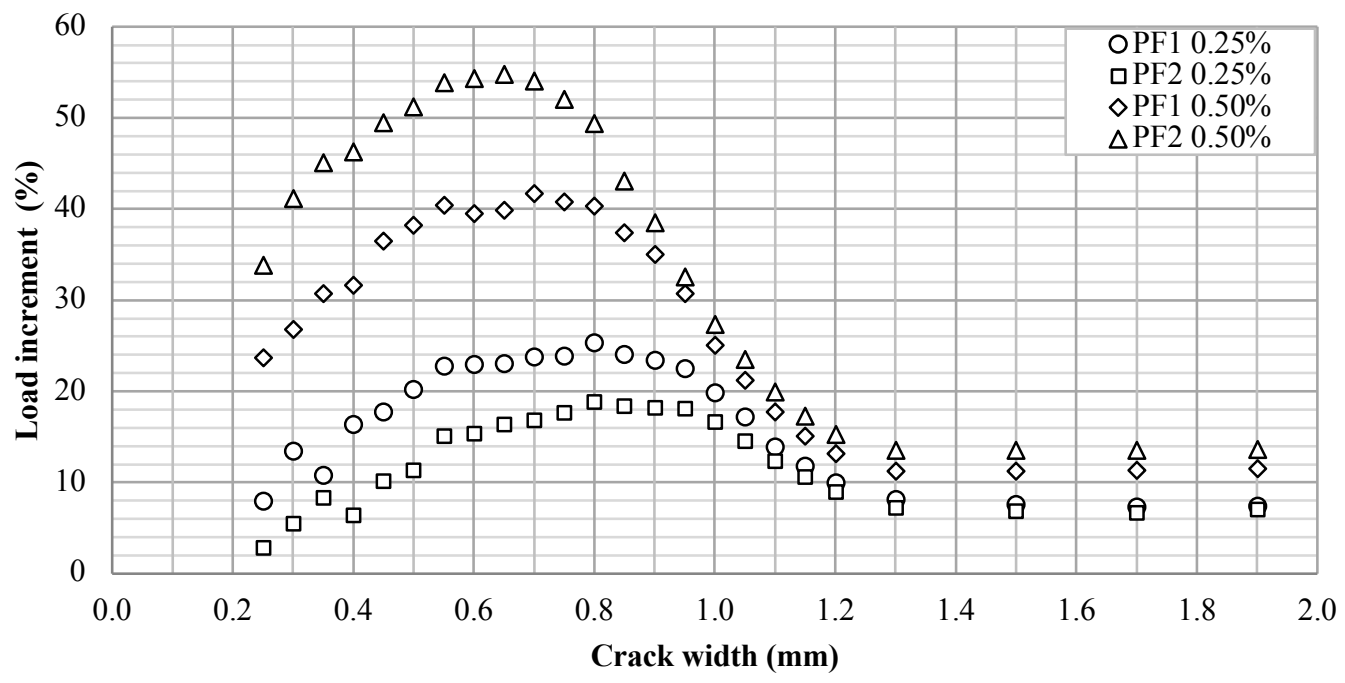

Figure 8. Percentage of increment in load-crack width curve. Polypropylene fibers

In figure 7, both types of fibers have a high aspect ratio, but one of them is nearly twice as long as the other (see table 1). For the amount of $0.25 \%$ in volume, the elements with short fibers (SF1) begin working before those with long fibers (SF2) do, since the load increments admitted for small crack widths are higher. However, the SF2 elements admit higher load increments once the in-service stage has been surpassed, more specifically from a crack width of $0.8 \mathrm{~mm}$ onward. This behavior is due to the fact that the fibers with different sizes begin working and turn out to be more efficient in different stages of the cracking process [27] and [47].

The short fibers take part in the bridging of the cracks when they are small since the number of short fibers in the concrete is higher than the number of long ones, providing an increment in the residual strength for small crack widths. As cracks grow bigger and become macrocracks, the longest fibers become more active in the bridging process improving the ductility and the residual strength [18], since some of the short ones have already lost anchorage. Nonetheless, the behavior just described does not 
repeat itself in the in serviceability limit state for the amount of $0.50 \%$ in volume. In this case, both types of elements (SF1 and SF2) offer a very similar response (the increments of SF2, with long fibers, being slightly higher). One of the possible reasons for this difference is put forward later on, on the basis of figure 9. For higher cracking widths, however, it is fulfilled that the long fibers are more active and, therefore, higher load increments are admitted.

In both figures ( 7 and 8), in the last section of the curve the load increase becomes stable and remains more or less constant from a crack width of $1.3 \mathrm{~mm}$ onward, with percentage increments with regard to the RC elements of $8.8 \%$ and $11.6 \%$ for SF1 and SF2, and 8.1\% and 7.2\% for PF1 and PF2, respectively (for the fiber amount of $0.25 \%$ in volume); of $18.0 \%$ and $21.6 \%$ for SF1, SF2; $11.3 \%$ and $13.6 \%$ for PF1 and PF2 (for the fiber amount of $0.50 \%$ in volume).

Figure 9a shows the contribution of each of the components of FRC in the stress-strain curve of FRC. The previously described tendency (figures 7 and 8) about load increase is outlined in figure $9 \mathrm{~b}$, indicating also the various stages and relating them to the stress-strain curve of FRC.
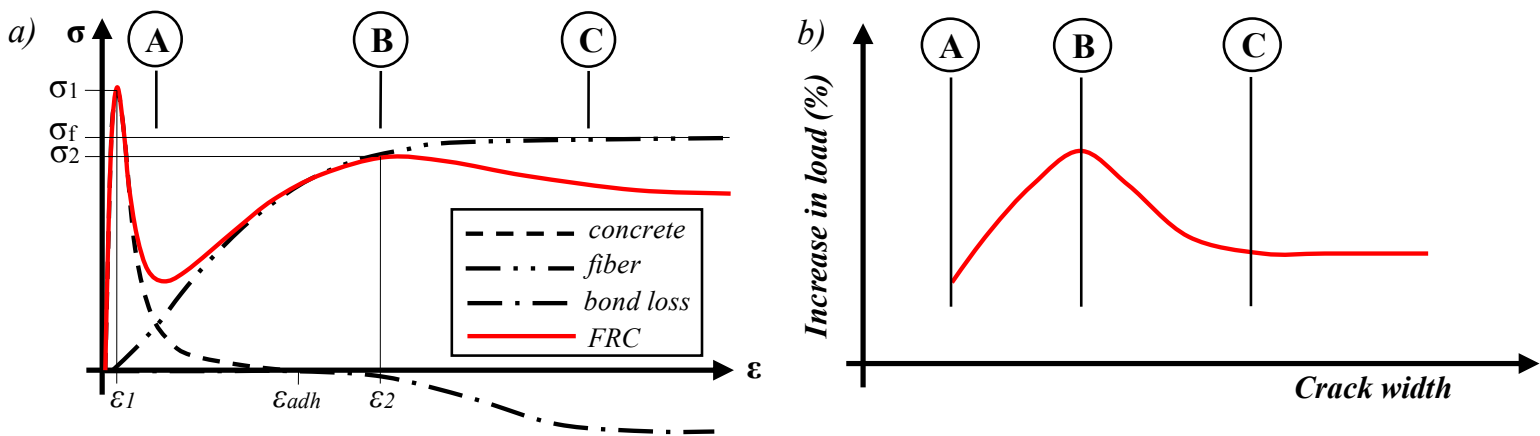

Figure 9. (a) Contribution of each component of FRC to the stress-strain model; (b) Diagram of the behavior observed in figures 12 and 13.

The diagram in figure 9a coincides with the direct approach proposed in [48], which starts from studying concrete with fibers as a superposition of three factors: mass concrete, fibers and the interaction between both materials (adherence loss). The superposition of each of these phenomena shows the growing contribution of fibers after the cracking of the concrete matrix $\left(\sigma_{1}, \varepsilon_{1}\right)$ up to a maximum residual stress $\left(\sigma_{2}\right)$ which is conditioned by the interaction between the materials. During crack growth and under a scenario of perfect bond conditions, the strengthening contribution of all the fibers in the cross-section would be equal to the one of a steel rebar, increasing progressively until its tensile yield strength is achieved. However, in most of the situations fibers are pulled out from the cement matrix and, consequently, a specific bond strength law has to be considered to account for the pullout behavior of fibers. This interaction usually leads to a loss of adherence, beginning with $\varepsilon_{\text {adh }}, \sigma_{2}$ being lower than the theoretical maximum contribution of the fibers $\left(\sigma_{\mathrm{f}}\right)$. This has been represented as a negative stress (figure 9a) trying to show, in this conceptual point of view or philosophy approach, that the debonding leads to a loss in the fibers contribution. More details of this FRC approach can be found in [14]. 
As a result of what has been stated, in figure $9 \mathrm{~b}$ three stages can be identified. After an instantaneous loss of stiffness due to cracking, the contribution of fibers begins in point $\mathrm{A}$, which results in an increase in load admissible for a given crack width with regard to the slabs without fibers. The contribution of fibers grows up to point $\mathrm{B}$, the moment when the fibers reach their maximum efficiency (or maximum contribution). The slope of that section (A-B) is ruled by the type and amount of fibers. From point B onward, fibers lose adherence and slide, which results in a reduction of load increment with regard to the slabs without fibers, until it becomes stable from point $\mathrm{C}$ on, when fibers work under a pullout mechanism.

\subsubsection{Analysis of efficiency}

In figure 10 a more detailed analysis of the serviceability limit state (considering a maximum crack width of $0.5 \mathrm{~mm}$ ) is shown. For this purpose, the quotient between the load increment (\%) for a given crack width was calculated for each type and amount of fibers, and then it was divided by the maximum load increment detected in figures 7 and 8 . This value is indicative of the efficiency of the fiber for small crack widths, that is, it shows how close to its maximum contribution for the different crack widths the fiber is.
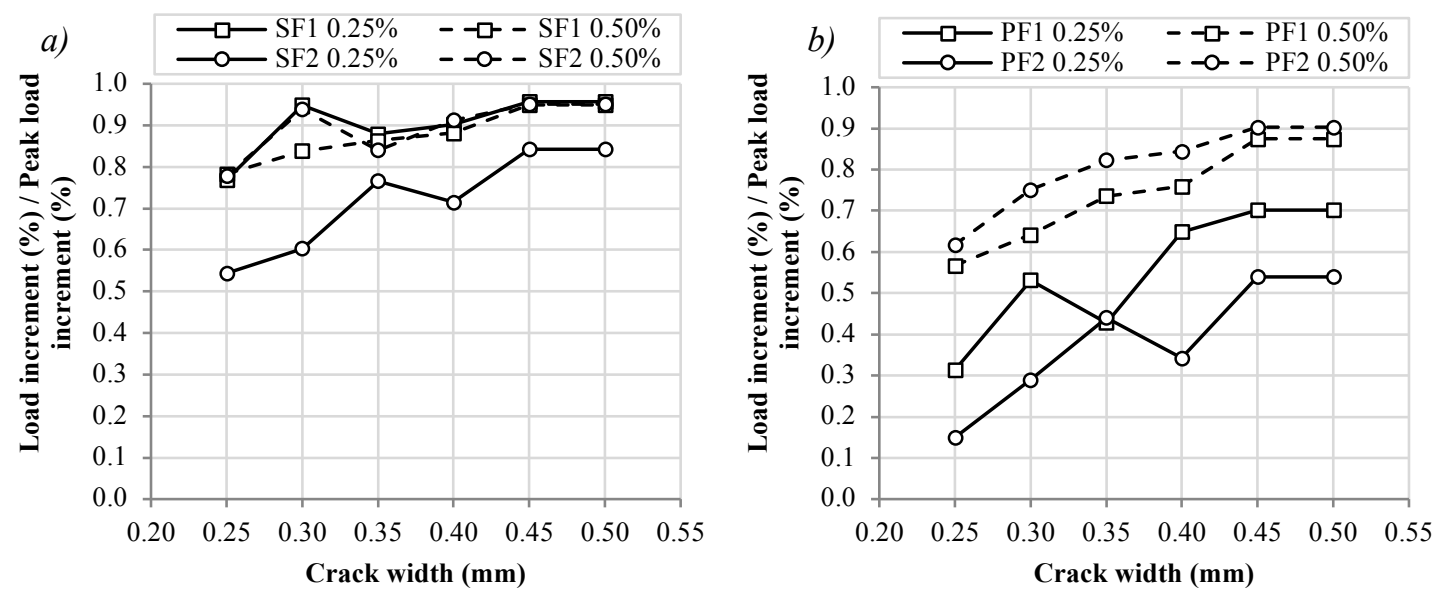

Figure 10. Efficiency of the fiber versus crack width at serviceability limit state.

The values in figure 10 indicate that steel fibers have a behavior close to their maximum contribution (values close to 1) from the moment cracking begins (efficiencies ranging from $60 \%$ to $90 \%$ ). The polypropylene fibers do not reach such a high performance for the crack widths studied (from $0.25 \mathrm{~mm}$ to $0.50 \mathrm{~mm}$ ) in figure 7 with values ranging from $20 \%$ to $80 \%$. This phenomenon indicates a higher efficiency of the steel fibers for lower widths, favoring cracking control from the first stages of crack formation. Likewise, it is observed that for the smallest dosage $(0.25 \%$ in volume) the short steel fiber (SF1) shows values higher than those of the long fiber (SF2), developing a contribution closer to the maximum one for small crack widths. An explanation for this phenomenon can be found in the higher number of fibers crossing the cracks.

The results indicate that the amount of fibers plays a promiment role in the global behaviour as has already been reported in other studies [49] and [9].This fact is more evident in the case of the chosen dosages of polypropylene fibers.

\subsection{Deflection}




\subsubsection{Serviceability limit state analysis}

For this analysis, displacements of the midspan up to $5 \mathrm{~mm}$ are considered, thus the load-displacement curves are limited to that range of deflection. Figure 11 shows the curves for of each pair of elements (element A and element B) corresponding to an amount of fibers, for example: SF1 0.25\%_A and PF1 0.55\%_B.
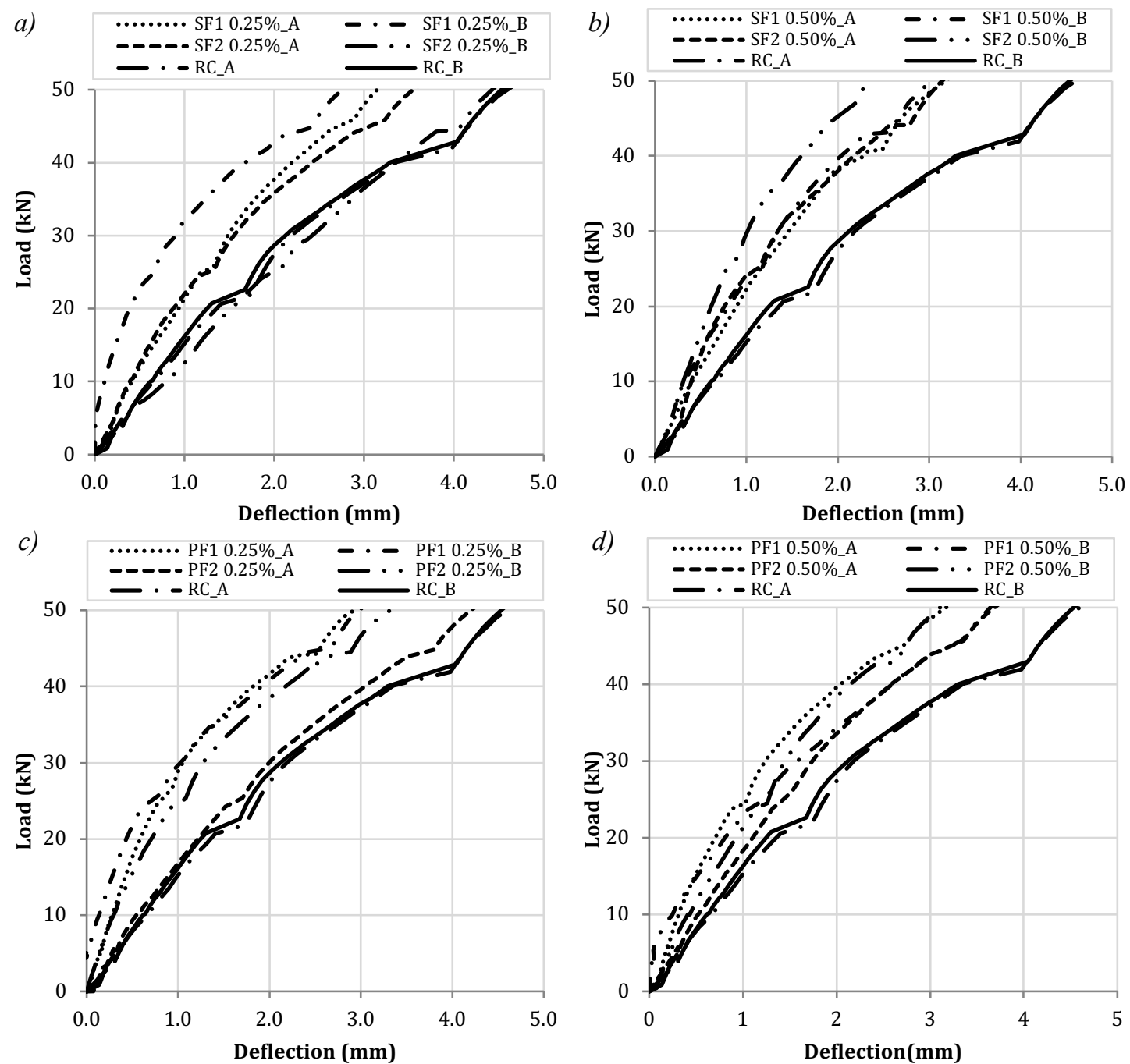

Figure 11. Load-deflection curves in serviceability limit state for steel fibers (a), (b) and polypropylene fibers (c), (d) for both fiber contents: $0.25 \%$ and $0.50 \%$ in volume.

In figure 11a the elements showing a better behavior turn out to be the SF1 $0.25 \%$. In figure $11 \mathrm{~b}$, while for the SF2 elements there is a clear improvement in the behavior when the amount of fibers is doubled, this does not take place in the SF1 elements. In the case of elements with polypropylene fibers, PF1 $0.25 \%$ (figure 11c) elements are the ones showing the best result and, in the cases of both PF1 and PF2, the increase in the amount of fibers does not result in an improvement of the behavior in service (figure 11d).

\subsubsection{Ultimate limit state analysis}


The measurement of deflection has been recorded by means of displacement transducers in the midspan of the slab. Figure 12 shows the load-displacement curves for the two types and two amounts of fibers, $0.25 \%$ and $0.50 \%$ in volume.
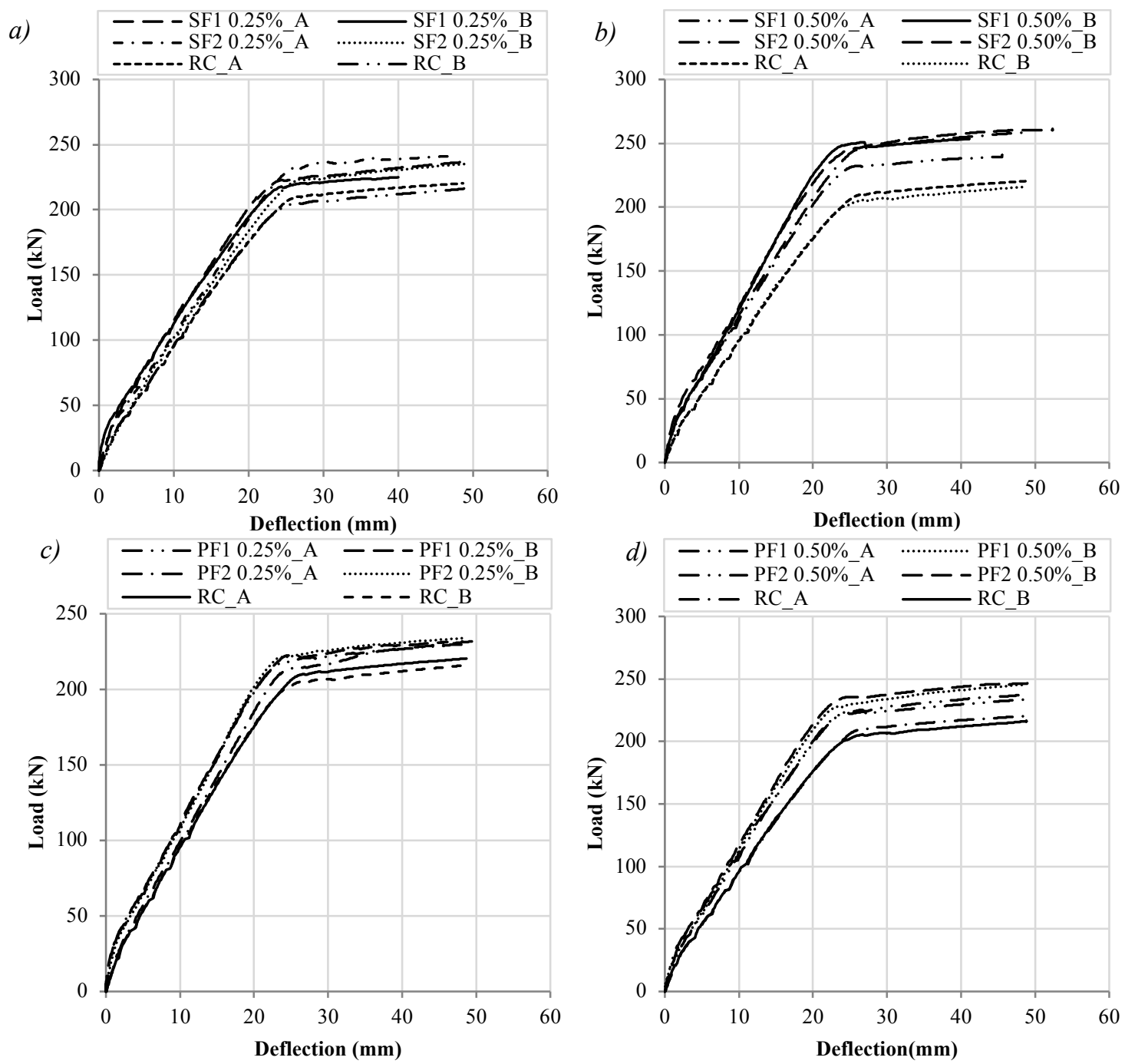

Figure 12. Load-deflection curves for fiber content of $0.25 \%$ and $0.50 \%$.

Taking a deflection of $30 \mathrm{~mm}$ (value that corresponds to the stabilization of the fiber contribution mentioned in section 4.2.3) as a reference, it is now analyzed the contribution of the fibers with respect to the RC elements. The addition of $0.25 \%$ of fibers means a load increment for the given value of deflection of $5.7 \%, 8.7 \%$ for SF1 and SF2 (in figure 12a) and 5.4\%, 4.5\% for PF1 and PF2 (figure 182b). Doubling the dosage (figure 12c and 12d), the load increment also doubles for $30 \mathrm{~mm}$ of deflection. The percentages in that case are $13.9 \%, 17.7 \%, 8.3 \%, 9.9 \%$ for SF1, SF2, PF1 and PF2 respectively.

In the load-displacement curves shown in figure 12, three stages can be distinguished: pre-cracking, post-cracking and yielding of the reinforcement.

In the first stage, a linear behavior can be assumed for any of the materials the section is made of. This linear behavior between stresses and strains of the materials is maintained until concrete cracks when it reaches a strain stress $f_{c t m}$, which takes place at 


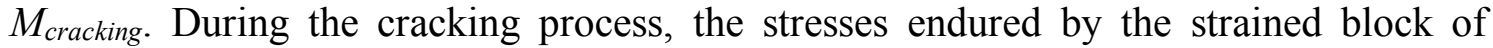
concrete are transmitted to the steel through the mechanisms of adherence and compatibility of strain existing between them.

During the second stage, concrete has cracked and both the steel bars and the fibers begin to develop their resistance task. Finally, the third stage corresponds to the load section subsequent to the yielding of the reinforcement.

In order to be able to analyze the behavior of each of the tested slabs, the slope of the lines which make up each of the three stages has been calculated. A linear behavior of the element is accepted for the three stages, but non-sectional in the second and third ones due to cracking; therefore, the global behavior is not linear. Table 6 shows the values of the slopes (expressed in $\mathrm{kN} / \mathrm{mm}$ ) of the three stages for each of the elements studied.

\begin{tabular}{ccccc}
\hline $\begin{array}{c}\text { Fiber } \\
\text { content }\end{array}$ & Specimen & Stage 1 & Stage 2 & Stage 3 \\
\hline \multirow{2}{*}{0} & RC_A & 16.5 & 7.90 & 0.373 \\
& RC_B & 14.6 & 7.90 & 0.389 \\
\multirow{2}{*}{$0.25 \%$} & SF1_A & 20.7 & 8.80 & 0.548 \\
& SF1_B & 38.4 & 8.40 & 0.457 \\
\multirow{2}{*}{$0.25 \%$} & SF2_A & 21.9 & 8.90 & 0.682 \\
& SF2_B & 12.5 & 8.20 & 0.577 \\
\hline \multirow{2}{*}{$0.25 \%$} & PF1_A & 33.3 & 9.01 & 0.417 \\
& PF1_B & 33.6 & 9.34 & 0.404 \\
\multirow{2}{*}{$0.25 \%$} & PF2_A & 16.8 & 8.73 & 0.514 \\
& PF2_B & 25.7 & 9.65 & 0.441 \\
\hline \multirow{2}{*}{$0.50 \%$} & SF1_A & 20.7 & 9.20 & 0.711 \\
& SF1_B & 22.7 & 10.90 & 0.687 \\
\multirow{2}{*}{$0.50 \%$} & SF2_A & 31.7 & 9.40 & 0.751 \\
& SF2_B & 34.1 & 10.40 & 0.805 \\
\hline \multirow{2}{*}{$0.50 \%$} & PF1_A & 29.4 & 9.03 & 0.539 \\
\multirow{2}{*}{$0.50 \%$} & PF1_B & 18.9 & 10.04 & 0.517 \\
\hline & PF2_A & 18.3 & 9.18 & 0.514 \\
& PF2_B & 20.3 & 10.10 & 0.616 \\
\hline
\end{tabular}

Table 6. Slope of the load-deflection curve for each stage (in $\mathrm{kN} / \mathrm{mm}$ ).

The values in table 6 are indicative of the previously described behavior. Regardless of the fact that the experimental campaign is not wide enough to propose firm conclusions about it, it can be noticed that the addition of fibers implies an increase of the slope studied for all the cases and stages object of analysis. This increase is especially significant in the first stage. That would mean, then, that the addition of fibers significantly modifies the elastic module of concrete. In the second stage there is a decrease in stiffness due to the cracking of the matrix. The same occurs in the third stage when, after the plastification of the reinforcement, the curve slope diminishes until it becomes almost horizontal.

It must be noted that in these stages the contribution of the fibers also involves an increase of the slope, even if not as pronounced as in the first stage, and with small 
differences between the type and amount of fibers used. Since the only difference that exists between the various slabs as regards materials is the type of fiber, there should not be noticeable differences in the curve slopes before cracking. In that stage the strengthening action of the fibers has not yet been activated, therefore the behavior of the elements should be practically identical. However, the values in table 6 show differences in the slopes of the stage prior to cracking.

A comparison between the experimental stiffness and the theoretical stiffness (calculated by means of a numerical model of sectional analysis [31]) can be found in [39], where the experimental and theoretical load-displacement curves corresponding to the experimental campaign herein presented are plotted.

\subsubsection{Energy absorption capacity}

The addition of fibers has a very significant influence over the energy absorption capacity of concrete, this being one of the properties most benefitted by the presence of the fibers [50], [51] and [52]. Given the influence of the energy absorption capacity over the behavior of the structure, especially over elements such as segmental lining or slabs on soil [53] and [54], there are in the literature numerous approaches to the evaluation of said property: toughness indexes, factor of toughness under deflection and fracture energy [55], [56] and [57].

The definition of toughness in terms of energy absorption, according to JSCESF4, 1984 [56], is calculated for a standard-sized sample as the area under the loaddisplacement curve up to a limit of $\mathrm{L} / 150$. There exist similar indexes proposed in other regulations, such as IBN, 1992 [58]; DBV 1991 [59], 1992a [60], 1992b [61] and AENOR UNE 83-510 [62].

In this case, an approximation of the absorbed energy was carried out on the basis of the load-displacement relationship recorded during the tests by calculating the area under said curve. Table 7 shows the results of absorbed energy (for a displacement at midspan of $40 \mathrm{~mm}$ of the tested slabs) depending on the type of reinforcement. Likewise, the increase in energy absorption capacity as a result of the addition of fibers, with regard to the reference element (RC), is also indicated.

\begin{tabular}{ccc}
\hline Reinforcement & $\begin{array}{c}\text { Absorbed Energy } \\
\text { (kNmm) }\end{array}$ & Increase (\%) \\
\hline RC & 5997.5 & - \\
\hline SF1 0.25\% & 6646.6 & $10.82 \%$ \\
SF2 0.25\% & 6520.0 & $8.71 \%$ \\
\hline PF1 0.25\% & 6620.0 & $10.38 \%$ \\
PF2 0.25\% & 6456.7 & $7.66 \%$ \\
\hline SF1 0.50\% & 7092.3 & $18.25 \%$ \\
SF2 0.50\% & 7262.5 & $21.09 \%$ \\
\hline PF1 0.50\% & 6778.9 & $13.03 \%$ \\
PF2 0.50\% & 6849.6 & $14.21 \%$ \\
\hline
\end{tabular}




\begin{tabular}{cc}
\hline Reinforcement & $\begin{array}{c}\text { Mean } \\
\text { Increase (\%) }\end{array}$ \\
\hline RC & - \\
\hline SF 0.25\% & $9.76 \%$ \\
\hline PF 0.25\% & $9.02 \%$ \\
\hline SF 0.50\% & $19.67 \%$ \\
\hline PF 0.50\% & $13.62 \%$ \\
\hline
\end{tabular}

reinforced with fibers with regard to the RC elements. For a dosage of $0.25 \%$ in volume of fibers the contribution in terms of absorbed energy is practically identical (between $9 \%$ and $10 \%$ ) for plastic fibers (PF) and steel fibers (SF). However, while the steel fibers (SF) double the increase in absorbed energy when the dosage is doubled (an average of $19.67 \%$ for the dosage of $0.50 \%$ ), the plastic fibers do not yield such satisfactory results (an average of $13.62 \%$ for the dosage of $0.50 \%$ ).

\section{CONCLUSIONS}

On the basis of the elements herein presented and the results obtained from testing them, the following conclusions can be reached:

- The addition of fibers diminishes the spacing between cracks owing to a higher transmission of stresses to concrete through adherence mechanisms. Nevertheless, even though generally speaking crack spacing decreases as dosage increases, in certain cases said relationship is not so clear.

- The formulation for the prediction of crack spacing proposed in [4] and [6] provides lower values compared to the experimental results. This formulation, based on experiences with beam-type elements, should perhaps be revised for bidirectional elements (slabs or plates with transversal reinforcement).

- The contribution of the fibers to cracking control in terms of crack width is significant when the amount is doubled with most types of fibers (the SF1 elements have shown a more similar behavior with both amounts of fiber).

- The action of the fibers in service increases until it reaches its maximum efficiency with crack widths around 0.55 and $0.8 \mathrm{~mm}$ (depending on the type and amount of fibers). The stabilization of the action of the fibers takes place in ELU with values close to a crack width of 1.2-1.4 mm.

- The short steel fibers turn out to be the most active as regards cracking control in the first stages of formation.

- The contribution of the fibers and their efficiency is the result of the global behavior of the fiber-reinforced concrete, that is, of the superposition of the following factors: concrete, fibers, adherence loss and, in this case, also the conventional reinforcement.

- The influence of fibers in deflection control is visible at all stages of the test, but it is particularly significant at serviceability limit state.

- The absorbed energy shows how for small amounts of fiber $(0.25 \%)$ there are hardly any differences between the polypropylene fibers $(+9.02 \%)$ and steel fibers $(+9.75 \%)$, however doubling the amount of fibers $(0.50 \%)$ these differences become more evident. 
- The number of polypropylene fibers is greater than the steel fibers, the contribution of steel fibers (highest form that the plastic) is significantly doubling the contribution increased by doubling the amount.

\section{ACKNOWLEDGMENTS}

In memory of Professor Luis Agulló, for his outstanding contribution to this project, his unconditional dedication to the teaching of engineers and his unforgettable friendship.

The authors would like to thank the companies Bekaert and Grace for the material supply and to Bekaert, in particular, for its active collaboration in the project. Likewise, the authors appreciate the comments and opinions of Professor L. Vandewalle. The authors would like to express special thanks to Marc Vandewalle for his initiative and constant support during the research.

The authors acknowledge the support of the Spanish Ministry of Science and Innovation (MICINN) in the scope of the project CONSFIB (reference: BIA 1010-17478). The first and second author acknowledge the grant FPI - UPC provided by the UPC and the grant FI provided by the Comissionat per a Universitats del DIUE de la Generalitat de Catalunya $i$ del Fons Social Europeu, respectively. The first and second authors also acknowledge the support of the Col-legi d'Enginyers de Camins, Canals $i$ Ports de Catalunya.

\section{REFERENCES}

[1] SERNA, P.; ARANGO, S.; RIBEIRO, T.; NÚÑEZ, A.M.; GARCIA-TAENGUA, E. "Structural cast-in-place FRC: technology, control criteria and recent applications in Spain". Materials and Structures, Accepted 11 June 2009 (DOI: 10.1617/s11527-0099540-9).

[2] DI PRISCO, M.; PLIZZARI, G.; VANDEWALLE L. "Fiber reinforced concrete: new design perspectives", Materials and Structures, Accepted 11 June 2009 (DOI: 10.1617/s11527-009-9529-4).

[3] DBV Merkblatt Stahlfaserbeton, Deutsche Beton Vereins, 2001.

[4] CNR-DT 204 "Istruzioni per la Progettazione, l'Esecuzione ed il Controllo di Strutture Fibrorinforzato", Consiglio Nazionale delle Riserche, Italia, 2006.

[5] EHE-08 "Instrucción del Hormigón Estructural", Comisión Permanente del Hormigón, Ministerio de Fomento, 2008.

[6] RILEM TC 162-TDF "Test and design methods for steel fiber reinforced concrete", Materials and Structures, 2000, Vol. 33, pp. 75-81.

[7] BENCARDINO, F.; RIZZUTI, L.; SPADEA, G.; SWAMY R.N. "Stress-Strain Behavior of Steel Fiber-Reinforced Concrete in Compression", Journal of Materials in Civil Engineering, 2008, Vol. 20, No.3, pp. 255-263. 
[8] BARROS, J. A. O.; FIGUEIRAS, J. A. "Flexural behavior of SFRC: testing and modeling", Journal of Materials in Civil Engineering, 1999, Vol.11, Issue 4, pp. 331339.

[9] BARROS, J. A. O.; CUNHA, V.M.C.F.; RIBEIRO, A.F.; ANTUNES, J.A.B. "Postcracking behaviour of steel fiber reinforced concrete", Materials and Structures Journal, 2005, Vol.38, pp. 47-56.

[10] JONES, P.A.; AUSTIN, S.A.; ROBINS, P.J. "Predicting the flexural loaddeflection response of steel fiber reinforced concrete from strain, crack-width, fiber pull-out and distribution data", Materials and Structures, 2008, Vol.41, pp. 449-463.

[11] SUJIVORAKUL, C.; WAAS, A.M.; NAAMAN, A.E. "Pullout response of a smooth fiber with an end anchorage", Journal of Engineering Mechanics, 2000, Vol. 126, No. 9, pp.986-993.

[12] EASLEY, T.C.; FABER, K.T.; SHAH, S.P. "Use of a Crack-Bridging Single-Fiber Pullout Test to Study Steel Fiber/Cementitious Matrix Composites", Journal of the American Ceramic Society, Vol. 82, No.12, pp. 3513-3520.

[13] BANHOLZER, B.; BRAMESHUBER, W.; JUNG, W. "Analytical evaluation of pull-out tests-The inverse problem", Cement and Concrete Composites, 2006, Vol. 28, pp. 564-571.

[14] LARANJEIRA, F.; "Design-oriented constitutive model for steel fiber reinforced concrete", PhD Thesis, Universitat Politècnica de Catalunya, 2010.

[15] BARRAGÁN, B. "Failure and toughness of steel fiber reinforced concrete under tension and Shear", PhD Thesis, Universitat Politècnica de Catalunya, 2002.

[16] BISCHOFF, P. H. "Tension stiffening and cracking of steel fiber-reinforced concrete", Journal of Materials in Civil Engineering, March 2003, Vol.15, Issue 2, pp. 174-182.

[17] CACHIM, P.B.; FIGUEIRAS, J.A.; PEREIRA, P.A.A. "Fatigue behavior of fiberreinforced concrete in compression", Cement and Concrete Composites, 2002, Vol. 24, pp. 211-217.

[18] MARKOVIC, I. "High-Performance Hybrid-Fiber Reinforced Concrete: Development and Utilisation”. PhD Thesis, Delft University of Technology, 2006.

[19] VANDEWALLE, L."Hybrid fiber concrete: is there a synergetic effect?", Advances in Construction Materials, 2007, Part II pp.219-228.

[20] QIAN, C. X.; STROEVEN, P. "Development of hybrid polypropylene-steel fiber reinforced concrete", Cement and Concrete Research, 2000, Vol.3, pp.63-69. 
[21] ESWARI, S.; RAGHUNATH, P. N.; SUGUNA, K. "Ductility Performance of Hybrid Fiber Reinforced Concrete", American Journal of Applied Sciences, 2008, Vol.5, No.9; pp.1257-1262.

[22] ADEEN, M. Z.; AL-ATTAR, A. A.; RA'OUF, S. M. "Determination of Mechanical Properties of Hybrid Steel-Nylon Fiber Reinforced Concrete", Modern Applied Science, 2010, Vol.4, No.12, 97-108.

[23] CHIAIA, B.; FANTILLI, A.P.; VALLINI, P. "Evaluation of minimum reinforcement ratio in FRC members and application to tunnel linings", 2007, Materials and Structures, Vol. 40, pp. 593-604.

[24] HAKTANIR, T.; ARI, K.; ALTUN, F.; KARAHAN, O. "A comparative experimental investigation of concrete, reinforced-concrete and steel-fiber concrete pipes under three-edge-bearing test", Construction Building Materials, 2007, Vol. 21, pp. 1702-1708.

[25] CHIAIA, B.; FANTILLI, A.P.; VALLINI, P. "Evaluation of crack width in FRC structures and application to tunnel linings", Materials and Structures, 2009, Vol. 42, pp. 339-351.

[26] VANDEWALLE, L. "Cracking behavior of concrete beams with a combination of ordinary reinforcement and steel fibers", Materials and Structures, April 2000, vol. 33, pp. 164-170.

[27] SORELLI, L.G.; MEDA, A.; PLIZZARI, G.A. "Steel Fiber Concrete Slabs on Ground: A Structural Matter", ACI Structural Journal, July-August 2006, Vol.103, No.4, pp. 551-558.

[28] FIGUEIREDO, A.D. "Evaluation of the test method for crushing strength of steel fiber reinforced concrete pipes", Proceedings of the Seventh RILEM International Symposium (BEFIB 2008), 17-19 September, Chennai (India).

[29] PUJADAS, P. "Durabilidad del hormigón con fibras de polipropileno", Minor Thesis, Universitat Politècnica de Catalunya, 2008.

[30] BLANCO, A. "Durabilidad del hormigón con fibras de acero", Minor Thesis, Universitat Politècnica de Catalunya, 2008.

[31] DE LA FUENTE, A.; AGUADO, A.; MOLINS, C. "Modelo numérico para el análisis no lineal de secciones prefabricadas construidas evolutivamente", Hormigón y Acero, 2008, Vol. 57, No.247, pp. 69-87.

[32] ENV 1992-1-1. Eurocode 2: Design of Concrete Structures - Part 1: General rules and rules for buildings, CEN, 1992.

[33] EN 12390-3:2009 "Testing hardened concrete. Compressive strength of test specimens", 2009. 
[34] EN 14651:2005 "Test method for metallic fiberred concrete - Measuring the flexural tensile strength (limit of proportionality (LOP), residual)", 2005.

[35] PARMENTIER, B., VANDEWALLE, L. and VAN RICKSTAL, F. "Dispersion of the mechanical properties of FRC investigated by different bending tests", Tailor Made Concrete Structures, Walraven and Stoelhost, eds, Taylor\& Francis Group, Amsterdam, 2008, pp. 507512.

[36] MOLINS, C.; AGUADO, A.; SALUDES, S. "Double Punch Test to control the energy dissipation of FRC (Barcelona test)", Materials and Structures, Vol.42, No. 4, 2009 pp. 415425 .

[37] VANDEWALLE, L."Hybrid fiber reinforced concrete", Measuring, Monitoring and Modeling Concrete Properties, M.S Konsta-Gdoutos, ed.,Springer, 2006, pp.77-82.

[38] FIB MODEL CODE 2010 (First complete draft), Fédération Internationale du Béton, 2010.

[39] BLANCO, A.; PUJADAS, P.; DE LA FUENTE, A.; AGUADO, A. "Análisis comparativo de los modelos constitutivos del hormigón reforzado con fibras", Hormigón y Acero, 2010, Vol.61, No.256, pp.83-101.

[40] TAN, K-H.; PARAMSIVAM, P.; TAN, K-C. "Cracking characteristics of Reinforced Steel Fiber Concrete Beams under Short- and Long-Term Loading", Advanced Cement Based Materials, 1995, Vol.2, pp.127-137.

[41] MINDESS, S. "Fiber reinforced concrete: Challenges and prospects", Fiber reinforced concrete, N. Banthia and S. Mindess, eds., $2^{\text {nd }}$ University-Industry Workshop on Fiber Reinforced Concrete and Other Advanced Composites, Toronto, 1995, pp.111 .

[42] HARAILI, M.; HAMAD, B.; KARAM, K. "Bond slip response of reinforcing bars embedded in plain and fiber concrete", Journal of Materials in Civil Engineering, Vol.14, No.6, pp.503-511.

[43] RIZK, E.; MARZOUK, H. "A New Formula to Calculate Crack Spacing for Concrete Plates", ACI Structural Journal, 2010, Vol.107, No.1, pp. 43-52.

[44] FERNÁNDEZ RUIZ, M. "Evaluación no lineal de los efectos estructurales producidos por las deformaciones diferidas del hormigón y el acero", $\mathrm{PhD}$ Thesis, Universidad Politécnica de Madrid, 2003.

[45] LEE, S.L.; MANSUR, M.A.; TAN, K.H.; KASIRAJU, K. "Crack control in beams using deformed wire fabric", Journal of Structural Engineering, 1989, Vol.115, No.10, pp.2645-2660.

[46] CENTRE SCIENTIFIQUE ET TECHNIQUE DE LA CONSTRUCTION (CSTC). "Sols industriels à base de ciment", Note d'Information Technique 204, Juin 1997. 
[47] LAWLER, J.S.; ZAMPINE, D.; SHAH, S.P. "Microfiber and Macrofiber Hybrid Fiber-Reinforced Concrete", Journal of Materials in Civil Engineering, 2005, Vol.17, No.5, pp. 595-604

[48] AGUADO, A.; LARANJEIRA, F. "Presentación del Anejo de Hormigón con Fibras de la EHE y ecuación constitutiva del Hormigón Reforzado con Fibras", Avances en tecnología del hormigón en construcción subterránea, Jornada Técnica 2007-JT-01, 23 de mayo de 2007, Barcelona, 2007, pp. 1-32.

[49] BALAGURU, P. N.; SHAH, S. P. Fiber-Reinforced Cement Composites, McGrawHill Inc.,New York, 1992.

[50] State-of-the-Art Report on Fiber Reinforced Concrete. ACI 544. 1R-96, ACI Manual of Concrete Practice, Part 5, ACI International, Farmington Mills, MI, 1997.

[51] GOPALARATNAN, V.S.; SHAH, S. P.; BATSON, G. B.; CRISWELL, M. E.; RAMAKRISHNAN, V.; WECHARATONA, M. Fracture Toughness of Fiber Reinforced Concrete, ACI Materials Journal, 1991, Vol.88, No. 4, pp.339-353.

[52] BARROS, J. A. O. "Comportamento do Betão Reforçado com Fibras-Análise Experimental e Simulação Numérica", PhD Thesis, Faculty of Engineering, University of Porto, 1995.

[53] BARROS, J.A. O.; FIGUEIRAS, J. A. "Experimental Behaviour of Fiber Concrete Slabs on Soil", Journal of Mechanics of Cohesive-Frictional Materials, 1998, Vol. 3, Issue 3, pp.277-290.

[54] BARROS, J. A. O. "Experimental Behavior of Mesh Reinforced Shotcrete and Steel Fiber Reinforced Shotcrete Panels", Int. Conf. of the European Ready Mixed Concrete Organization, ERMCO’98, Lisboa, Portugal, 1998.

[55] ASTM C1018-89: Standard test method for flexural toughness and first-crack strength of fiber-reinfoorced concrete (using beam with third-point loading)."ASTM, West Conskohocken, Pa, 1991.

[56] JSCE-SF4: "Method of test for flexural strength and flexural toughness of steelfiber.reinforced concrete", Concrete library of Japan Society of Civil Engineers (JSCE), 1984, Vol. 3, pp.58-61.

[57] HILLERBORG, A., MODEER, M., PETERSSON, AND P.E. "Analysis of crack formation and crack growthin concrete by menas of fracture mechanics and finite elements". Cement and Concrete Research, 1986, Vol.6, pp.773-782.

[58] IBN 1992 "Essais des betons reforces de fibers- Essai de flexion sur eprouvettes prismatiques", Norme Belge NBN B 15-238, Institute Belge de Normalisation (IBN), 1040 Brussels, pp.9.

[59] DBV 1991 "Grundlagen zur Bemessung von Industrielufböden aus Stahlfaserbeton", Deustchen Beton - Vereins, pp. 2578-272. 
[60] DBV 1992a "Technologie des Stahlfaser-betons und Stahlfaserspritzbetons", Deustchen Beton-Vereins, pp. 3-18.

[61] DBV 1992b "Bernessungsgrundlagen fur Stahlfaserbetons in tunnelbau", Deustchen Beton-Vereins, pp. 19-43.

[62] AENOR UNE 83-510 "Hormigones con fibras. Determinación del índice de tenacidad y resistencia a primera fisura", Madrid, España. 